\title{
A História do Instituto de Psiquiatria do Hospital das Clínicas e do Departamento de Psiquiatria da Faculdade de Medicina da Universidade de São Paulo
}

\author{
Jorge Wohwey Ferreira Amaro ${ }^{1}$
}

Fui convidado pelo Prof. Dr. Hélio Elkis (Coordenador do Curso de Pós-Graduação) e pelo Prof. Dr. Zacaria Borge Ali Ramadam (Chefe do Departamento de Psiquiatria da FMUSP) para elaborar um artigo sobre o histórico do Instituto de Psiquiatria e do Departamento de Psiquiatria da FMUSP para ilustrar e comemorar o Jubileu do Instituto de Psiquiatria da FMUSP nos seus 50 anos de existência. Senti imensa responsabilidade devido a vários motivos. Primeiro, é uma honra para mim e para qualquer colega ser distinguido como representante desta busca do histórico dessa respeitável Instituição. Além disso, o Instituto e o Departamento de Psiquiatria da FMUSP estão em um patamar de sua existência que precisa ser muito bem descrito e resumido. Neste novo milênio devemos, além do histórico, simplesmente descritivo e rememorar o passado, organizar uma ponte de interligação entre o passado, o presente e o futuro. Se possível extrair dos aspectos descritivos históricos uma dinâmica dos movimentos sociodinâmicos na Ciência Psiquiátrica e no famoso Zeit Geist.

A palavra História designa o relato sobre a sequiência de acontecimentos realizados ou sofridos pelos homens no passado, conhecimento que pôde ser adquirido por meio da tradição ou da pesquisa de documentos e de sua análise. Por meio da Filosofia da História, podemos tentar compreender a seqüência dos acontecimentos, admitindo-se que ela não é incoerente e casual, mas segue um movimento determinado, segundo certas linhas de força. Embora esse conhecimento não nos permita prever o futuro com clareza, pode nos indicar um sentido ou uma direção. As doutrinas clássicas da Filosofia da História apresentam diversas correntes, como o Idealismo Histórico, representado por Hegel, e o Materialismo Histórico, representado por Marx e Engels.

Como sabemos, o historicismo pode ser considerado um método filosófico que tenta explicar, por meio da História, os acontecimentos relevantes do direito, da moral, da religião etc. Dentro dessa corrente filosófica, existem aqueles que fazem da História o fundamento de uma concepção geral do mundo (historicismo filosófico, propriamente dito), enquanto outros recusam toda e qualquer concepção do mundo, vendo na História apenas uma das condições de inteligibilidade do real (historicismo epistemológico). Se, de um lado, a História pode ser tida como expressão dos relatos escritos ou falados do curso dos acontecimentos, de outro a investigação filosófica e crítica da História leva-nos a buscar o significado que se situa além da esfera da história-relato, enquadrando-a no aspecto do conhecimento. Os filósofos da História escrevem-na com sua atenção voltada para a filosofia da ciência. É necessário termos uma visão global dos relatos da História para depois tentarmos compreendê-la.

\footnotetext{
Professor Associado Permissionário do Departamento de Psiquiatria da FMUSP.

Endereço para correspondência:

Av. Paulista, 2073 - Horsa I - sala 403 - CEP 01311-300

Tel.: (0xx11) 288-3472

E-mail: jwohweyfa@aol.com
} 
Necessitamos lembrar a História e compreendêla para podermos aproveitar o acervo de conhecimentos deixados pelos modelos referenciais de nossos antecessores e, a partir daí, modificá-los e ampliá-los com novas contribuições. Sêneca já dizia: "Apliquis vir bonus nobis elidendus est, ac semper ante oculos habendus, ut sie tamquam illo spectante vivãmus et omnia tamquam illo vidente faciãmus" (Devemos escolher algum modelo que tenhamos sempre perante os olhos, de modo a vivermos sempre como se ele nos estivesse a olhar e procedermos como se ele nos visse).

Os modelos referenciais usados por nossos antecessores nas décadas de 1950 e 1960 muito nos honraram e foram a bússola que nós, profissionais do Instituto de Psiquiatria, usamos. A partir das décadas de 1950 e 1960 houve uma modificação dos modelos referenciais de enfoque da etiopsicopatologia. Algumas datas devem ser citadas para entendermos a história e a dinâmica desses modelos. Em 1933, Sakel introduz o coma insulínico no tratamento das afecções mentais. Em 1935, Von Meduna dá início ao emprego da convulsoterapia por meio do pentametilenotretasol por via endovenosa. Em 1937, Cerletti e Bini empregam a corrente elétrica para obtenção de convulsões no tratamento de várias psicoses. Esses modelos foram usados de maneira empírica, uma vez que pouco se conhecia da etiopatogenia e dos mecanismos de ação desses tratamentos. Sou da época em que esses modelos foram a base dos tratamentos psiquiátricos. A moderna psicofarmacologia só se iniciou após 1950, quando então somente se dispunha dos tratamentos supradescritos. Pacheco e Silva e Henrique Marques de Carvalho, desde 1937, passaram a usar a insulinoterapia e também a convulsoterapia.

Em 1952, Laborit, em seus estudos sobre anestesia, averiguou o efeito calmante de um derivado fenotiazínico. A partir das observações de Laborit passou-se a utilizar a clorpromazina em doses crescentes no arsenal terapêutico psiquiátrico. Nessa mesma data a clorpromazina já era muito utilizada no pré-anestésico. Eu, durante minha atividade no campo da anestesia, já usava a clorpromazina (Amplictil ${ }^{\circledR}$, Dolantina ${ }^{\circledR}$ e Fenergan ${ }^{\circledR}$ ) como pré-anestésico. O Instituto de Psiquiatria, após o seu início, em 1952, passou a utilizar essa recente psicofarmacologia, publicando vários artigos sobre o uso da clorpromazina. Na década de 1950, após a descoberta da clorpromazina, sucede-se uma enxurrada de descobertas ou sínteses de substâncias psicotrópicas. Surgiu um elevado número de neurolépticos, destinados ao tratamento principalmente das psicoses, bem como drogas inibidoras das monoaminoxidases e antidepressivos denominados tricíclicos para o tratamento das síndromes depressivas e também drogas tranqüilizantes, para o alívio da ansiedade.
Aos poucos a psicofarmacoterapia vai relegando ao esquecimento antigos processos de tratamento, com exceção da convulsoterapia elétrica. Com o sucesso dos resultados do tratamento psicofarmacológico, houve um grande estímulo ao desenvolvimento do estudo dos neurotransmissores que hoje ocupam a base dos estudos da etiopatogenia dos quadros psiquiátricos. Contudo, a lentidão do avanço desse conhecimento que usou décadas de intensas pesquisas no campo da psicofarmacologia e dos neurotransmissores e seus mecanismos, da biologia molecular e da genética propiciou um vácuo que permitiu que o "psicologismo", por meio da Psicanálise e de outros referenciais, tentasse sempre explicar as etiopatogenias por causas psicológicas. A culpa não foi da Psicanálise nem da Psicologia. Foi de quem as mal usou e não suportou a dolorosa espera do avanço dos conhecimentos supradescritos. Sou testemunha viva, como assistente que fui do Prof. Pacheco e Silva, de que ele lutou para que os seus assistentes jamais deixassem de pesquisar as bases bioquímicas e genéticas na Psiquiatria. Ele era, injustamente, chamado de "organicista". O próprio Freud, em seus trabalhos, já havia dito que toda aquela estrutura psicodinâmica seria um dia explicada em bases orgânicas.

Pacheco e Silva nunca foi contra a Psicanálise, mas sim contra aqueles que se desviavam da busca dessa moderna visão da Psiquiatria e se fixavam em "psicologismos". O Prof. Pacheco e Silva, naquela ocasião, em seu livro de Psiquiatria Clínica e Forense se referia à esquizofrenia: "A que se poderá atribuir o aparecimento destes distúrbios psíquicos de evolução tantas vezes irremediável, que inutiliza tantos jovens, alguns de inteligência aguda e de numerosos predicados intelectuais e morais? Nisso está um dos grandes enigmas da Psiquiatria. Se muitas vezes há uma causa próxima como hereditária, tóxica ou infecciosa, que explique o advento das perturbações psíquicas que deflagram na puberdade, em outras, não há elementos precisos que permitam conclusões seguras".

Nessa mesma ocasião, o Prof. Mira y Lopez escrevia em relação à esquizofrenia: "Se trata de uma afecção mental essencialmente unitária, endógena, orgânica devida a causas tóxicas de natureza desconhecida". Como vemos, nessas décadas anteriores, sem o atual conhecimento da intensa participação dos neurotransmissores, das alterações morfológicas dos centros nervosos (por falta da moderna aparelhagem de neuroimagem), da moderna pesquisa em genética e da moderna psicofarmacologia, promovendo um vazio no conhecimento, propiciou-se que muitos psicanalistas se colocassem a decifrar a esquizofrenia, os quadros maníacos depressivos, os quadros obsessivo-compulsivos etc., como regressões a fases primitivas, como se a 
etiologia fosse devida a núcleos primitivos desencadeadores do quadro clínico. Havia uma crença, nessa época, de correlacionar distúrbios psiquiátricos a causas conflitivas psicológicas negadas no consciente. Esse mau uso da Psicanálise, junto com o crescimento da moderna Psiquiatria, propiciou o descrédito do uso da Psicanálise pelos psiquiatras. Caiu-se no extremo oposto. A Psicanálise bem usada e dentro dos seus limites ainda é um grande auxiliar dentro da Psiquiatria, desde que o psicoterapeuta conheça bem psicopatologia. Alguns psicanalistas acreditavam que por meio de interpretações corretas e bem colocadas poderiam evitar uma reagudização da sintomatologia dos pacientes psicóticos. Eles viam a psicose como uma doença que tinha mais a ver com as experiências nas fases mais precoces do desenvolvimento da vida do indivíduo e que seriam etiologicamente a causa do problema.

A grande dificuldade da Psicanálise naquela ocasião é que havia a pretensão de apontar a psicose como etiologicamente dependente de regressões aos pontos de fixação em fases primitivas do desenvolvimento da criança, devido a conflitos, também primitivos, não solucionados. A pergunta que se fazia na época era: por que as psicoses surgiam quinze, vinte, trinta anos após o nascimento? Como um ego tão comprometido em seu desenvolvimento inicial só iria sucumbir tantos anos depois? Essas perguntas eram respondidas de maneira pouco convincente e sem evidências comprováveis, como, por exemplo, de que seriam núcleos psicóticos que se manifestariam em situações externas conflitivas, que desencadeariam os conflitos psicóticos reprimidos. Tanto na psicose maníaco-depressiva como na esquizofrenia, os resultados da aplicação exclusiva da psicanálise mostravam-se pouco operantes, enquanto as drogas psicotrópicas apresentavam resultados comprováveis, bem como os mecanismos bioquímicos nas sinapses neuronais.

Em 1946, Darcy de Mendonça Uchoa defendeu sua tese de docência-livre de Clínica Psiquiátrica na FMUSP intitulada A Estrutura Psicológica da Neurose Compulsiva. Sob a influência da época, a sua tese caminhou no sentido de colocar os transtornos psicológicos da neurose compulsiva como etiologicamente dependentes de conflitos psicológicos. Na sua conclusão número 9, afirma: "não tem qualquer indicação na neurose compulsiva a terapêutica medicamentosa de rotina". Na sua conclusão número 5, afirma: "podemos concluir que fatores patogênicos de ordem somática, quando existem, são secundários e não essenciais". Na sua conclusão número 4 , diz: "fatores psicogênicos sob forma de intensos e não resolvidos conflitos intrapsíquicos, atuando a modo de fundos e repetidos "traumas psíquicos", mostraram-se constantes em nosso material.
Não raro a análise mental cuidadosa verificou que a sintomatologia neurótica era apenas uma acentuação de traços caracterológicos, "formação de reação" por parte de um ego em oposição a fortes solicitações da vida instintiva fundamental (sexualidade e agressividade). Determinadas constelações atuais, tensões emocionais em relação com conflitos atuais, pondo-se mais ou menos diretamente em conexão com os conflitos infantis, reativando-os, desencadearam a sintomatologia compulsiva".

Como vemos, as conclusões são da forma como a Psicanálise era usada na época.

Como resultado, os psicanalistas tiveram que abrir mão da hipótese etiológica das psicoses e reiniciar a pesquisa com outro enfoque. Assim, não se aceitam hoje afirmações como "O indivíduo entrou em esquizofrenia por uma regressão psicótica à fase narcísica" ou "Ele ficou esquizofrênico devido a uma mãe esquizofrenogênica".

Atualmente, com o desenvolvimento científico de diferentes áreas de pesquisa, podemos investigar a etiologia dos transtornos mentais com maior evidência de suas conclusões. Durante as conversas que tive com o Prof. Pacheco e Silva na década de 1960, ao pretender fundar o Serviço de Psicoterapia, estando eu em formação psicanalítica, fui felizmente alertado por ele para não me desviar da busca das bases bioquímicas e genéticas em Psiquiatria e para que usasse a Psicanálise dentro de seus limites possíveis. Foi graças a ele que nunca fui picado pelo mosquito do "psicologismo" e continuo exercendo a Psicanálise dentro dos seus reais limites.

No início da década de 1960, além de freqüentar o Instituto de Psiquiatria por quase todas as manhãs, eu era chefe de plantões e plantonista do então chamado Centro de Triagem do Pronto-Socorro Psiquiátrico de Vila Mariana. Ali todo tipo de psicopatia aguda e crônica surgia de todos os cantos do país. O Prof. Pacheco e Silva incumbiu-me de selecionar alguns casos psiquiátricos que pudessem ter interesse para o ensino e que poderiam não surgir no nosso ambulatório, que recebia uma amostragem diferente de casos clínicos. Lembro-me de ter trazido um caso de paralisia geral juvenil, casos de alucinose alcoólica e muitos outros que enriqueciam o nosso arsenal clínico para o ensino. A idéia de um Pronto-Socorro Psiquiátrico no Instituto foi levantada. Cheguei, na ocasião, a publicar um artigo sobre Urgências Psiquiátricas com material do Centro de Triagem do Pronto-Socorro Psiquiátrico de Vila Mariana. Devido a problemas administrativos e ao perigo de o Instituto tornar-se depositário de todo e qualquer caso psiquiátrico do estado de São Paulo e de outros estados, o Professor Pacheco resolveu não instituir um Pronto-Socorro Psiquiátrico no Instituto de Psiquiatria. Lembro-me de que, em meus plantões lá no Pronto-Socorro Psiquiátrico de Vila Mariana, o número de pacientes sempre foi muito 
superior à capacidade de atendimento, além do fato de pacientes de todos os estados do Brasil irem até lá buscar auxílio.

O Instituto de Psiquiatria e o Departamento de Psiquiatria, desde seu início, acompanhavam e colaboravam para o avanço do conhecimento etiopatogênico baseado em evidências reais dentro do que se conhecia na época.

A pesquisa genética em transtornos mentais vinha demonstrando que a herança poligênica e multifatorial é fator importante na gênese da esquizofrenia. As pesquisas de todo genoma aceleraram novos avanços na detecção de genes de pequeno efeito. O Instituto de Psiquiatria, recebendo do Prof. Pacheco e Silva esta forte influência na busca das bases bioquímicas da Psiquiatria, resultou no que temos hoje.

O Prof. Valentim Gentil desde o início da década de 1980 já vinha pesquisando as bases biológicas da ansiedade em uma época em que a Psicologia e a Psicanálise ocupavam muito espaço na tentativa de compreender a ansiedade e o distúrbio do pânico.

O Prof. Gattaz vem organizando, no Instituto de Psiquiatria, um laboratório de investigações médicas em neurociências, onde pesquisadores estão alargando nossos horizontes quanto à etiologia dos transtornos mentais. Uma das pesquisas é a alteração do metabolismo dos fosfolípides e sua correlação com a esquizofrenia. O Prof. Eurípedes Miguel vem centrando seus esforços, com a colaboração de pesquisadores estrangeiros, na pesquisa das bases bioquímicas e genéticas de quadros obsessivo-compulsivos. Em face desses novos conhecimentos, a Psicanálise poderá e deverá continuar sendo usada, porém com um novo enfoque. Poderá tentar compreender a comunicação e o material latente na expressão do quadro manifesto, porém com a prudência de não estabelecer relações etiológicas. $\mathrm{O}$ fortalecimento do ego adulto do paciente, pelo aumento do seu insight, deverá ajudá-lo a compreender-se e aliar-se ao ego adulto do terapeuta no sentido de tentar administrar sua situação existencial.

É importante que façamos um resumo histórico da Psiquiatria Infantil no Instituto de Psiquiatria da FMUSP.

Até a década de 1950, não existia em São Paulo um serviço médico especializado nos atendimentos de crianças e adolescentes portadores de distúrbios psíquicos; doentes graves, como os psicóticos, por exemplo, eram internados e tratados em hospitais psiquiátricos para adultos; distúrbios de comportamento e manifestações de características neuróticas eram atendidos em centros de psicologia que utilizavam, como terapêutica, unicamente métodos psicoterápicos ou psicopedagógicos. Na década de 1950 também não existia, em São
Paulo, hospital psiquiátrico pertencente a uma universidade, sendo as aulas de Psiquiatria de cursos médicos ministradas em hospitais públicos. O Prof. Pacheco e Silva, ao concluir e instalar o Instituto de Psiquiatria, teve a visão de buscar a instalação de um Setor de Psiquiatria Infantil. Ele, nessa mesma década, ministrando aulas de Psiquiatria, demonstrava aos estudantes de Medicina da FMUSP a importância do desenvolvimento do estudo e das pesquisas em Psiquiatria Infantil. Nessa ocasião, uma jovem estudante do 4 o ano médico, empolgada com a possibilidade de exercer a Psiquiatria Infantil, passou a dirigir sua vida acadêmica nesse sentido. Essa jovem estudante, hoje a Profa. Dra. Eneida Baptistete Matarazzo, decidiu, após sua formatura, permanecer um ano em residência médica em Pediatria; a seguir, mais um ano em Psiquiatria Geral e um outro ano de residência, que dessa vez seria dedicado exclusivamente à Psiquiatria Infantil. Isso só foi possível devido à visão pioneira de Pacheco e Silva, pois a seu pedido, a Comissão de Residência Médica do HC admitiu um terceiro ano de residência em Psiquiatria Infantil, sendo a médica Eneida Baptistete Matarazzo contemplada nessa fase pioneira.

Como vimos nesse relatório histórico, o Prof. Pacheco e Silva e o próprio Instituto de Psiquiatria recebiam nessa ocasião forte influência francesa. Nessa época, na Europa, a especialidade Psiquiatria Infantil se consolidava. Por sugestão do Prof. Pacheco e Silva, essa jovem médica e pioneira na busca do aperfeiçoamento da Psiquiatria Infantil candidatou-se a uma bolsa de estudos do governo francês para estagiar na Clinique de Neuropsychiatrie Infantile do Hospital Salpetrière, em Paris, considerado na ocasião um dos melhores da Europa. Nesse ano de estágio em Paris, aproveitou, durante um mês de férias de seu estágio, para permanecer um mês no Serviço de Psiquiatria Infantil do Maudsley Hospital, em Londres. Ao retornar, em 1960, agora com uma bagagem de experiência em Psiquiatria Infantil, pôde realizar o seu desejo de participar da criação de um Setor de Psiquiatria Infantil na Clínica Psiquiátrica.

Naquele tempo era costume do Departamento de Psiquiatria colocar um livre-docente como responsável por Setores e Serviços no Instituto de Psiquiatria, por isso o Prof. Carvalhal Ribas ficou como responsável pelo Setor de Psiquiatria Infantil. Eneida Baptistete Matarazzo e o Dr. Julcir Meirelles Penna, o qual trabalhara como pediatra até então, iniciaram o projeto pioneiro de atendimento ambulatorial de menores de até 17 anos, que eram encaminhados para tratamento de distúrbios psíquicos. Foi esse o início da institucionalização de um Setor de Psiquiatria Infantil no Instituto de Psiquiatria. Em 1961, foi criado oficialmente o Serviço de Psiquiatria da Infância e da Adolescência 
(SEPIA), que passou a funcionar em ambulatório próprio e em duas enfermarias, cada uma com 42 leitos. Eneida Baptistete Matarazzo foi quem, na prática, liderou e organizou o Serviço de Psiquiatria Infantil. Mais duas psiquiatras foram contratadas para colaborar nessa atividade: a Dra. Cacilda Cuba dos Santos e a Dra. Edi Navarro. Com o tempo a equipe foi aumentando, com a participação de uma psicóloga, uma assistente social, duas terapeutas ocupacionais, um corpo de enfermagem especializado em atendimento psiquiátrico e outros psiquiatras. De acordo com o costume da época, o Prof. Dr. João Carvalhal Ribas, como representante do Departamento de Psiquiatria, foi indicado como Chefe do SEPIA, porém, Eneida Baptistete Matarazzo continuava, na prática, liderando o desenvolvimento desse Serviço. Em 1976, após doutoramento e de tornar-se um dos membros do Departamento de Psiquiatria, Eneida Baptistete Matarazzo foi indicada como Chefe do SEPIA.

Após alguns anos de experiência, Eneida Baptistete Matarazzo e sua equipe constataram que o número de leitos para internação de menores era excessivo. Aceitando a sugestão de Eneida, o então Prof. Titular, Dr. Fernando de Oliveira Bastos, concordou com uma reforma que permitiu que o SEPIA ficasse com apenas uma enfermaria dividida em setor masculino e feminino, cada um com 16 leitos. Reconhecido como centro de excelência para atendimento psiquiátrico de menores, o SEPIA atendia número crescente de pacientes, justificando aumento progressivo de sua equipe multidisciplinar. Esse fato, associado à grande experiência prática de Eneida e seu grupo, levou-a a propor ao Departamento de Psiquiatria a criação de uma residência médica em Psiquiatria Infantil, com programação de três anos, sendo o primeiro deles em Psiquiatria Geral. Essa residência, pioneira no Brasil, forma especialistas desde 1974.

Com o reconhecimento e a valorização da disciplina Psiquiatria Infantil, o então Departamento de Neuropsiquiatria da FMUSP concordou, em 1977, que o concurso de Livre-Docência da Dra. Eneida Baptistete Matarazzo fosse realizado em Psiquiatria Infantil, dessa forma reconhecendo-a oficialmente como especialidade autônoma. A partir daí, mestrado, doutorado e livredocência passaram a poder ser realizados na área de Psiquiatria Infantil. O Serviço de Psiquiatria Infantil passou a ampliar suas atividades, como, por exemplo, estágio no SEPIA para médicos residentes do $\mathrm{HC}$ de outras especialidades; curso teórico-prático de um ano em Atualização em Psiquiatria Infantil; cursos e seminários; publicações de trabalhos científicos em revistas médicas nacionais e internacionais, publicações de livros relacionados à especialidade etc. Naquela época, com o apogeu da Psicanálise, era comum muitos considerarem o Instituto de Psiquiatria, em particular o SEPIA, dirigido por Eneida, como de "orientação organicista". Foi uma interpretação falsa de alguns indivíduos, pois sou testemunha viva de que Eneida Baptistete Matarazzo conhecia psicodinâmica, e tivemos, por coincidência, a oportunidade de participar juntos de um grupo organizado pelo Prof. Darcy de Mendonça Uchoa, o qual promovia, com suas interpretações psicanalíticas, a compreensão da psicodinâmica do grupo e de seus núcleos conflitivos. O que ocorria é que Eneida, como eu e muitos outros do Instituto de Psiquiatria, recebia do velho Prof. Pacheco e Silva os conselhos de não nos deixarmos picar pelo mosquito do "psicologismo" e buscarmos as reais evidências que promovem um distúrbio mental. Se de um lado Pacheco e Silva foi o idealizador e criador teórico do SEPIA, Eneida Baptistete Matarazzo foi a executora pioneira desse ideal.

É importante que se diga que o Serviço Social é um departamento que existiu desde o início do Instituto de Psiquiatria. A primeira responsável pela condução do Serviço Social no Instituto foi Mina Berezovsky, de 1953 a 1955 e, a seguir, Décio da Silva Barros, Valderez Bueno de Barros Fontes Bittencourt, Catarina Jorge João, Damares Vicente de Lima e, desde 1987, Takako Sumihiro Katsuda.

O trabalho tinha dois enfoques básicos: o estudo de casos sob o ponto de vista do diagnóstico social e a intervenção no sentido de visitas domiciliares, encaminhamento a outras instituições e fornecimento de auxílio concreto pecuniário após seleção e triagem socioeconômica. Nessa fase, o Serviço Social não tinha o seu campo de ação ampliado como o é hoje.

É importante que recordemos o início da Psicologia Médica no Instituto de Psiquiatria. O Prof. Carvalhal Ribas foi o responsável por essa disciplina e encarregou-me de organizar os grupos de estudantes e suas aulas. Somente em 1968 foi introduzido o Psicodrama no Instituto de Psiquiatria e, portanto, foi somente a partir daí que instituí o Role Playing como método de aprendizagem da relação médico-paciente, complementando o aprendizado das aulas teóricas. $\mathrm{O}$ primeiro artigo sobre o Role Playing na relação médico-paciente foi publicado por nós naquela época. Posteriormente, o ensino da Psicologia Médica ficou a cargo de Paulo Vaz de Arruda; a seguir, Clovis Martins; posteriormente Zacaria Borge Ali Ramadame, atualmente, Arthur Kaufman.

É também muito importante lembrarmos, no histórico, das valorosas pioneiras da Enfermagem que muito contribuíram para o Instituto de Psiquiatria nos seus primórdios e até o presente momento.

No início do funcionamento do Instituto de Psiquiatria já existiam duas escolas de enfermagem 
atuantes em São Paulo: a da Escola Paulista de Medicina e a Escola de Enfermagem anexa à FMUSP, a qual iniciara suas atividades em 1942.

Estavam no começo da especialização em Enfermagem Psiquiátrica. A primeira enfermeira designada foi Carmem Ângulo Dias. Essa enfermeira pioneira, em um pequeno ambulatório improvisado (o prédio ainda estava por terminar), organizou os primeiros atendimentos. Elizabeth Barcellos Muller, da Escola de Enfermagem da FMUSP, fornecia auxílio técnico para o grupo da Enfermagem. Por indicação da Direção Administrativa do Hospital das Clínicas, a enfermeira Zaida Cunha foi designada Chefe da Enfermagem do Instituto de Psiquiatria. Zaida planejou e organizou a estruturação.

Foi uma figura enérgica e que no seu comando refletia o caráter centralista da época dos catedráticos. No entanto, essa diretora foi também considerada uma pessoa extremamente humana e preocupada com os pacientes e com as pessoas que compunham a equipe da Enfermagem.

Muitas enfermeiras foram para o exterior buscar novos conhecimentos. O Kardex foi introduzido pela Prof. Elizabeth Barcellos Muller, da Escola de Enfermagem da USP. Neste eram registrados os exames de laboratório, os medicamentos e um pequeno histórico do diagnóstico do paciente. Foi o Dr. Walter Nelson Cardo quem orientou sobre o seu uso nas enfermarias, pois ele teve vivências nos Estados Unidos. O treinamento do pessoal de Enfermagem era supervisionado pelas duas enfermeiras que fizeram treinamento nos Estados Unidos, Elizabeth Barcelos Muller e Dinah C. Mathias.

Até o momento da elaboração deste resumo histórico, Inaiá Monteiro Mello, Chefe do Serviço de Enfermagem no IPq, aponta como uma mudança importante na Enfermagem do IPq a determinação do Conselho Federal de Enfermagem, a partir de 1986, de promover a profissionalização do atendente dessa área. Assim, gradativamente os atendentes foram sendo substituídos por auxiliares/técnicos de enfermagem, o que qualificou bastante o atendimento do Instituto de Psiquiatria. Segundo depoimento de Inaiá, uma grande evolução também se estabeleceu quando se romperam os grilhões que colocavam a enfermeira apenas para os cuidados físicos do paciente. Foi bastante estimulado o aprendizado e o emprego do relacionamento terapêutico (RT), que é a terapia focal específica do enfermeiro psiquiátrico. Na década de 1960, fui convidado a ministrar aulas de Psicoterapia para o curso de graduação das enfermeiras e também cursos de aprimoramento em Psicoterapia para profissionais sob a organização da Escola de Enfermagem. Desde aquele tempo eu lutava contra o preconceito da época de que Psicoterapia seria terreno exclusivo de médicos, impedindo o desenvolvimento do que hoje se chama RT. Felizmente isso foi superado e com a introdução da Terapia Cognitiva Comportamental diversos profissionais têm recebido treinamento para esse fim.

O Prof. Pacheco e Silva já se preocupava com a Terapia Ocupacional em Franco da Rocha e no Instituto estimulava o seu início. Foram as enfermeiras que, no início, se ocuparam do pioneirismo da Terapia Ocupacional no Instituto de Psiquiatria. Elas trouxeram uma máquina de costura do Hospital Central das Clínicas, os funcionários trouxeram agulhas e linhas, e todos iniciaram o ensino da costura aos pacientes, que faziam trabalhos posteriormente vendidos em exposição. Pacientes menos habilitados eram convidados a fazer bolinhas de algodão, dobrar roupas nas enfermarias etc. e, assim, o Setor de Terapia Ocupacional foi se esboçando. A secretária do Serviço de Enfermagem, Dra. Tazuro Moriyama, foi encaminhada ao Serviço de Ortopedia para fazer o Curso de Terapia Ocupacional. As atividades de Terapia Ocupacional foram se ampliando, com oficina de marcenaria para os homens e bordado, costuras e tricô para as mulheres. Na década de 1960 foi criado o Setor de Terapia Ocupacional, chefiado pela própria Tazuro e por mais três terapeutas ocupacionais. Nessa mesma década, mais especificamente em 1964, docentes iniciaram suas pesquisas sobre uso da terapia ocupacional em pacientes psiquiátricos. Foi Jayme Gonçalves, com sua tese de livredocência sobre o estudo da Terapia Ocupacional em esquizofrênicos, quem primeiro avançou em pesquisas científicas sobre Terapia Ocupacional dentro do Instituto de Psiquiatria.

Ainda nessa mesma década, as estudantes da Escola de Enfermagem da FMUSP eram levadas ao então chamado Pronto-Socorro Psiquiátrico de Vila Mariana, centro de atendimento e triagem do Departamento de Assistência aos Psicopatas do Estado. Ali viam e aprendiam a experiência de casos psiquiátricos agudos, bem como casos raros vindos de diferentes regiões do Brasil. Nessa época, tive a oportunidade de dar algumas aulas de Urgências Psiquiátricas in loco (Pronto-Socorro Psiquiátrico de Vila Mariana) às alunas da Escola de Enfermagem. Uma das enfermeiras antigas do IPQ, Evalda Cançado Arantes, tornou-se docente na Escola e enviava essas alunas para experienciar, in loco, as urgências em Psiquiatria, pois o Instituto de Psiquiatria não tinha pronto-socorro psiquiátrico. $\mathrm{O}$ intuito da Escola de Enfermagem era propiciar bom conhecimento do paciente psiquiátrico às estudantes de enfermagem.

Podemos dizer que o atual Serviço de Psicologia teve seu início com a psicóloga Sonia Letaif Lipzig. O Prof. Pacheco e Silva designou Sonia para organizar esse Serviço, que ainda não estava institucionalizado. No início, o Serviço tinha como atribuição unicamente 
executar exames psicológicos, elaborando diagnósticos. $\mathrm{Na}$ época, o grupo de Sonia ficava limitado a essas atividades, pois havia um certo preconceito de que as psicólogas não poderiam exercer a psicoterapia e deveriam limitar-se aos testes psicológicos. O Zeit Geist impedia uma ampliação do Serviço. Eu, que discordava desse posicionamento, procurava estimular a abertura do processo. Em conversas com Sonia, verificamos que era preciso esperar o momento viável. Sonia decidiu ir para a França, quando então foi substituída por Máximo Lamberto Stefano, que, por ser psicólogo e médico, não encontrou resistências para procurar ampliar o Serviço. O Serviço de Psicologia do Instituto de Psiquiatria do Hospital das Clínicas, como entidade oficialmente institucionalizada, iniciou suas atividades em 1977 e esteve subordinado à Divisão de Apoio Médico até 1995, quando passou a responder diretamente à Diretoria Executiva do IPq.

Os modelos antigos de visão, de atendimento e tratamento psiquiátrico foram, neste novo milênio, modificados e aperfeiçoados, e muito nos alegra poder participar dessa nova fase.

Os modelos e as contribuições de Franco da Rocha e de seus sucessores estão aí para olharmos e serem olhados no sentido de nos apercebermos do quanto de fato estamos contribuindo para ampliar o que já foi feito, e não apenas modificações pela influência do Zeit Geist.

Como sabemos, a Psiquiatria paulista teve suas raízes no eminente Franco da Rocha. A de Psiquiatria foi ocupada, após Franco da Rocha, por Enjolras Vampré. O Prof. Antonio Carlos Pacheco e Silva foi o seguinte a ocupá-la; seguiu-se, como Titular, o Prof. Fernando Bastos, o Prof. Carvalhal Ribas, o Prof. Albuquerque Fortes e, em 1994, tomou posse, através de memorável concurso, o Prof. Valentim Gentil Filho e finalmente, em 1996, pela primeira vez, com a instituição da existência de dois titulares simultâneos, na mesma Cadeira, tomou posse, também através de memorável concurso, o Prof. Wagner Gattaz, recém-vindo da Alemanha, onde era Titular de Cadeira Psiquiátrica.

O ensino de Psiquiatria na Faculdade de Medicina da Universidade de São Paulo era realizado em parte no Hospital de Juqueri, fundado e dirigido por Francisco Franco da Rocha, em parte no antigo recolhimento das Perdizes e também no Laboratório de Anatomia Patológica da Santa Casa e, a partir de 1936, no antigo casarão do Departamento de Assistência aos Psicopatas do Estado de São Paulo, à Av. Brigadeiro Luiz Antônio. Os primeiros psiquiatras pertencentes à equipe do Prof. Pacheco e Silva foram os professores Fernando de Oliveira Bastos, Cauby Novaes, Carvalhal Ribas e Aristóteles Cardo.

Uma das poucas entidades nosográficas em Psiquiatria que na ocasião podia garantir o estabele- cimento de relações de causa e efeito era a então chamada "paralisia geral", com suas diferentes formas de expressões psicopatológicas, cujos distúrbios eram atribuídos às lesões por alterações cerebrais advindas da lesão pelo Treponema pallidum. Nessa ocasião, a Psiquiatria buscava a descrição pormenorizada dos quadros clínicos (Psiquiatria Descritiva) e a administração terapêutica com os meios existentes nessa ocasião, os quais eram precários e de administração empírica. Os aspectos etiológicos não eram cientificamente evidenciáveis e comprovados, e a esse vazio houve uma fase de especulações e de teorias sem evidências comprováveis. Nessa ocasião, quando então a moderna neurociência e os neurotransmissores ainda não haviam aparecido, a Psicanálise, mal usada, foi utilizada para explicar como causas psicológicas distúrbios psicopatológicos que hoje sabemos terem origem em distúrbios bioquímicos e genéticos.

Francisco Franco da Rocha, nascido em Amparo, no interior de São Paulo, em 23 de agosto de 1864, formou-se médico aos 26 anos pela Faculdade de Medicina do Rio de Janeiro. Desde logo, demonstrou preferência pela Psiquiatria, despertando a atenção do seu mestre, Teixeira Brandão. Em 1893, foi nomeado médico alienista do Hospício Provisório de Alienados da cidade de São Paulo. Em 1895, começou-se a construir um novo asilo, em um terreno de 150 hectares, à margem da linha inglesa, junto da Estação de Juqueri, limitado de um lado pelo Rio Juqueri, que deu esse nome à localidade. Enquanto o novo hospital era construído, Franco da Rocha ia se aprofundando na especialidade e procurava atenuar as limitações do velho Hospício da Várzea do Carmo. Em 1895, foi nomeado diretor do novo hospital. Franco da Rocha residiu com a família ao lado do Hospital de Juqueri desde 1899 até sua aposentadoria. Em março de 1923, aos 58 anos, foi substituído pelo Prof. Pacheco e Silva, que continuou e ampliou o que seu mestre havia realizado.

Quando foi fundada a Faculdade de Medicina e Cirurgia de São Paulo, graças à iniciativa de Arnaldo Vieira de Carvalho, Franco da Rocha foi convidado a ocupar a Cadeira de Clínica Neuriática e Psiquiátrica, mediante contrato com o governo, de 1918 a 1923.

O Prof. Franco da Rocha revisava e reestudava questões polêmicas, como a epilepsia psíquica. Em 1919, em aulas, focaliza a Psicanálise, o que era inédito para a época, e, em 1927, participa da fundação de uma sociedade de Psicanálise, com ilustres professores e médicos psiquiatras paulistas. Em 1925, com o afastamento de Franco da Rocha, foi contratado Enjolras Vampré para ocupar a Cadeira de Clínica Neuriática e Psiquiátrica. O sucessor de Franco da Rocha encontrou muitos discípulos do antigo Titular e o conceito de um 
homem considerado de caráter firme, sério, amante do bem público e humilde.

Antonio Carlos Pacheco e Silva nasceu em 29 de maio de 1898, na cidade de São Paulo. Como Franco da Rocha, formou-se em Medicina pela Faculdade de Medicina do Rio de Janeiro, em 1920. Iniciou sua especialização em Psiquiatria e Neuropatologia, freqüentando várias clínicas européias. A sua cultura era predominantemente de influência francesa, assim como o francês era seu segundo idioma. Regressando ao Brasil, já com grande bagagem científica, passou a trabalhar no Hospital do Juqueri, do qual se tornou diretor em 1923, por indicação do Prof. Franco da Rocha. Contratado para reger a Cadeira de Psiquiatria Forense na Faculdade de Direito de São Paulo, ministra cursos nos anos de 1932 e 1933. Em 1935, submete-se às duras provas do concurso de Clínica Psiquiátrica na Faculdade de Medicina e conquista a cátedra com distinção. Era o primeiro Titular por concurso e o terceiro a reger a Cadeira desde o início. Um Titular da Cadeira de Psiquiatria com 37 anos de idade, muitos ideais, muita energia e vontade de mudanças. Os titulares jovens são os que mais se empenham a mudanças. O modelo que o Prof. Pacheco e Silva usava e transmitia aos seus assistentes tinha como base a influência francesa. Posteriormente muitos de seus assistentes foram buscar na Inglaterra e nos Estados Unidos novos modelos de enfoque da Psiquiatria.

Pacheco e Silva, quando já estava no Hospital de Franco da Rocha, instituiu o uso do "trabalho" como auxiliar no tratamento dos doentes mentais. Pacientes eram colocados para trabalhar na terra, plantando ou em serviços que os mantinham ocupados e para que não se confinassem nos seus sintomas. Naquela época havia preconceitos que admitiam "exploração" colocar o doente mental em situação de qualquer tipo de trabalho. Ali teve início a Terapia Ocupacional como instrumento auxiliar no tratamento do doente mental.

O Prof. Pacheco e Silva aposenta-se em 1967, sendo sucedido pelo Prof. Fernando de Oliveira Bastos, o segundo Titular por concurso e o quarto a reger a Cadeira de Psiquiatria.

O Prof. Pacheco e Silva, em sua gestão, preocupado com a assistência aos psicopatas e com o ensino da Psiquiatria aos alunos da Casa de Arnaldo, empenhou-se desde logo em implantar um hospital de psiquiatria universitário moderno para casos agudos no Campus do Hospital das Clínicas. Vencendo preconceitos em relação a doentes mentais próximos ao Hospital Geral, o Prof. Pacheco e Silva, com a colaboração do Prof. Benedito Montenegro, então Diretor da Faculdade de Medicina da USP, e do Prof. Jorge Americano, na ocasião Reitor da Universidade de São Paulo, conseguiu do Governo do Estado (na gestão do Dr. Fernando Costa) que fosse construído o prédio para a instalação da Clínica Psiquiátrica. O atual prédio do Instituto de Psiquiatria, projetado e construído graças aos esforços do Prof. Pacheco e Silva, começou a funcionar em 1952, quando ainda estava parcialmente concluído o edifício. Em 1952, começou a funcionar o ambulatório e, em fevereiro desse mesmo ano, o primeiro atendimento. A primeira internação ocorreu em outubro de 1953. O Setor de Registro e Estatística era coordenado pela Dra. Nei (Maria de Lourdes Martins), figura gentil que se interessava muito pelo Instituto e a ele dedicou-se até a sua aposentadoria. A equipe do Prof. Pacheco e Silva era constituída pelos médicos Henrique Fonseca Marques de Carvalho, Paulo Camargo, Jairo de Andrade e Silva, Armando Cauby Novais, Fernando de Oliveira Bastos, João Carvalhal Ribas, José Roberto de Albuquerque Fortes e Heinz Weber. Nos anos seguintes, foram contratados Jayme Gonçalves, Carlos de Morais Arantes, Clóvis Martins, Ivo Soares Bairão, Paulo Vaz de Arruda e Cláudia Severa Sampaio Fonseca. Em outubro de 1953, iniciaram-se as atividades da primeira enfermaria. A primeira guia de internação foi assinada por Pacheco e Silva e Henrique Fonseca Marques de Carvalho, em 8 de outubro de 1953. Nesse mesmo ano, inicia-se o Serviço de Eletroencefalografia, sob a direção de Jairo de Andrade e Silva e com a colaboração de Paulo Vaz de Arruda. Nos anos seguintes, Paulo Vaz de Arruda vai aos Estados Unidos para aperfeiçoamento em Eletroencefalografia. Com o seu retorno ao Instituto de Psiquiatria, torna-se líder no estudo e na aplicação da eletroencefalografia.

Nos anos seguintes, com o advento dos transplantes cardíacos, Paulo Vaz de Arruda foi intensamente solicitado para o estudo e a definição de morte por meio do eletroencefalograma, que daria o diagnóstico de morte cerebral como parâmetro de morte. Ele teve que enfrentar desafios postos pelos preconceituosos e pelos fanáticos religiosos, que insistiam ser o coração o parâmetro do diagnóstico de morte. O Prof. Pacheco e Silva, além de construir o prédio da Clínica Psiquiátrica, imprimiu orientação técnico-científica, estruturou a residência médica e, ao aposentar-se, deixou a Cátedra de Psiquiatria desdobrada em três disciplinas: Psicologia Médica, Medicina Psicossomática e Psiquiatria Clínica. O Prof. Pacheco e Silva queria que a Psiquiatria fosse assentada não só em diagnósticos descritivos, mas também no conhecimento e na pesquisa das bases orgânicas e bioquímicas do cérebro. O Prof. Públio Salles Silva, que havia permanecido em Montreal, trouxe muitos conhecimentos sobre a Neuropsicocirurgia, com a finalidade de pesquisa, ensino e tratamento dos distúrbios do sistema nervoso cujos quadros 
psiquiátricos fossem suscetíveis de correção por meio de intervenções cirúrgicas. O Prof. Públio Salles Silva foi convidado a organizar o Serviço de Neuropsicocirurgia.

Em minhas conversas com Públio, homem gentil e extremamente erudito, recebi dele a pergunta: "Amaro, você, que é psicanalista, como pode explicar que um determinado paciente, portador de um foco temporal único e bem localizado, submetido a um implante de ouro radioativo, mudasse o seu temperamento de pessoa violenta, beligerante, inquieta e irascível para uma pessoa tranqüila?”. Já era mais uma comunicação do perigo de colocar os conflitos intrapsíquicos como responsáveis pela etiologia dos quadros psiquiátricos. $\mathrm{O}$ ouro radioativo não teria efeito na estrutura do conflito, mas sim na "situação existencial".

A partir de 1971, o Serviço foi assumido pelo Prof. Raul Marino, que deu a ele um impulso admirável.

Antes de vir para o Instituto de Psiquiatria, Raul Marino era preceptor dos residentes no Departamento de Neurologia e era ligado ao grupo do Tenuto (famoso neurocirurgião na época). No início, Raul Marino começou a operar epilepsia, hipófise, casos de dor crônica, casos de psicocirurgia etc. Ele conseguiu verbas vultosas com as quais pôde financiar o projeto de estruturar o Serviço de Neuropsicocirurgia Funcional. Contratou médicos, técnicos, eletroencefalografistas, engenheiros, psicólogos etc. Fundou o primeiro Serviço de Neuropsicologia, que hoje está sob a direção de Cândida Helena Pires de Camargo. Sou testemunha de conversas com Raul Marino em que pude constatar seu conhecimento de Psicodinâmica e seu interesse em integrar a Neurologia de base orgânica com os conhecimentos da Psicologia e da Psicanálise. Publicou o primeiro livro de Neurocirurgia Funcional em Nova York: Functional Neurosurgery. A Neurocirurgia funcional difundiu-se por todo o mundo, porém a Neurocirurgia Funcional existente no Instituto de Psiquiatria foi a primeira a funcionar como um Serviço individualizado. Havia muitas objeções a essa separação entre a Neurocirurgia Funcional e a Neurocirurgia Convencional.

A Neurocirurgia Funcional no Instituto de Psiquiatria produzia artigos inéditos; teses tanto no campo da Neuropsiquiatria como no da Neuroendocrinologia e da Neuropsicologia. Raul Marino levou os resultados de sua equipe a diversos congressos, e a partir daí foi convidado para ser membro de muitas sociedades mundiais de Neurocirurgia (atualmente é membro de 40 sociedades); tudo isso graças aos artigos e às pesquisas oriundas do Serviço de Neurocirurgia Funcional do Instituto de Psiquiatria da FMUSP. Em 1990, abriu-se concurso no Departamento de Neurologia da FMUSP para Titular da Cadeira de Neurocirurgia, quando então Raul Marino, em memorável concurso, venceu seu concorrente e passou a ser Titular dessa Cadeira. A partir daí ele procurou unificar os dois Serviços: Neuropsicocirurgia Funcional do Instituto de Psiquiatria e o Departamento de Neurologia com a Cadeira de Neurocirurgia. Raul Marino convidou o Dr. Ermírio de Moraes para ser o presidente da Fundação, o CENEPSI, e com isso tem conseguido doações que propiciam a manutenção e a ampliação do Serviço. Sem dúvida, Raul Marino foi pioneiro no campo da Neurocirurgia Funcional e contribuiu enormemente com o estudo das emoções, principalmente sobre o sistema límbico, mudando muitas vezes o pensamento psiquiátrico por meio de suas novas descobertas.

Atualmente, Raul Marino, após integrar os dois Serviços por ele unificados, está promovendo pesquisas experimentais em animais com uma equipe especializada (por exemplo, com a presença do Prof. César Timo Iária) cujos resultados serão de alta valia para a Psiquiatria e para a Neurologia.

O Instituto de Psiquiatria Prof. Dr. A. C. Pacheco e Silva, pertencente ao complexo do Hospital das Clínicas da FMUSP, alcançou, em sua existência, renome nacional e internacional. $\mathrm{O}$ elevado conceito da Instituição e do Departamento de Psiquiatria foi construído vagarosamente pela competência e seriedade com que foi dirigido no passado pelos antigos professores e atualmente pelos professores Valentim Gentil Filho e Wagner F. Gattaz.

Pacheco e Silva, além dos méritos descritos, deixou como herança muitos assistentes e colaboradores que se desenvolveram e procuraram acompanhar o estímulo do mestre. Em 1964, o Prof. Pacheco e Silva era assessorado por muitos assistentes competentes, bem como por dois professores livres-docentes: Fernando Bastos e Carvalhal Ribas. Estimulou outros assistentes a defenderem a livre-docência e, nessa ocasião, quatro de seus assistentes se tornaram professores livresdocentes: Henrique Marques de Carvalho (com a tese Contribuição para o Estudo das Modernas Terapêuticas Biológicas nos Estados Depressivos - 1964), José Roberto de Albuquerque Fortes (com a tese Psilocibina e Alcoolismo Crônico: Contribuição para o Estudos Somáticos e Psíquicos em Trinta Casos - 1964), Clóvis Martins (com a tese A Psicose Lisérgica: Psicopatologia da Percepção do Tempo e da Despersonalização-1964) e Jayme Gonçalves (com a tese Do Asilo à Comunidade Terapêutica: Contribuição para o Estudo da Terapêutica Ocupacional em Esquizofrênicos - 1964).

O corpo docente concursado se ampliava. Nessa ocasião, o Prof. Pacheco e Silva contava com muitos 
assistentes em atividade na pesquisa, no ensino e na assistência, entre eles Eneida Baptistete Matarazzo, Paulo Vaz de Arruda, Walter Nelson Cardo, eu e muitos outros. Nessa ocasião, estávamos preocupados com o ensino da Psicoterapia nas suas diferentes modalidades. De 1961 a 1962, enquanto trabalhava no ambulatório do Instituto de Psiquiatria, constatava que não havia um Serviço especializado para Psicoterapia. O que se fazia era atendimento psiquiátrico e psicoterapia de apoio.

Estando eu, na ocasião, em formação psicanalítica, pensei em consultar o Titular da Cadeira de Psiquiatria, o Prof. Pacheco e Silva, no sentido de aproveitar um pequeno espaço do então chamado hospital-dia e organizar um Serviço de Psicoterapia com as técnicas mais conhecidas e usadas na ocasião, que eram a Psicanálise, a Psicoterapia de Grupo e a Terapia Comportamental. Havia um boato, que se espalhara entre muitos psiquiatras dentro e fora do Instituto de Psiquiatria, no sentido de que o Prof. Pacheco e Silva era contra a Psicanálise e que, se eu fosse conversar com ele para organizar esse Serviço, corria o risco de receber uma reprovação. Fui conversar com o Prof. Pacheco e Silva e este concordou plenamente que eu organizasse o Serviço de Psicoterapia, mas alertou-me de que era apenas contra psicoterapeutas que não conheciam Psicopatologia Psiquiátrica e que promoviam prejuízos aos pacientes devido ao "psicologismo" e ao "furor interpretandis" desses mesmos psicoterapeutas. Concordei plenamente com ele e, a partir daí, após a sua autorização, fui convidar alguns colegas para comigo iniciarem a estruturação do chamado, na ocasião, Setor de Psicoterapia, pois não havia ainda a institucionalização oficial do Serviço, o que aconteceu em 1965.

Os primeiros colegas que ali chegaram foram Luiz Manoel da Silva, Lázaro Gross Sharf, Aníbal Mezher, A. C. Eva, H. C. Machado e muitos outros. Chegamos a atender 15 grupos psicoterápicos naquela ocasião, todos eles com referencial psicanalítico, uma vez que o Psicodrama, em 1965, não havia sido introduzido no Brasil, assim como outros referenciais careciam de pessoal habilitado. A demanda de Psicoterapia que o Ambulatório de Psiquiatria enviava era tão grande que nos levou a organizar o então chamado "banco de espera". Após uma triagem no Serviço de Psicoterapia, feita por um psicoterapeuta treinado, os pacientes selecionados eram introduzidos nos grupos já existentes e, na falta de vagas, iam para o "banco de espera" e seus dados eram colocados em uma ficha, para posterior convocação.

Em 1968, o Dr. Rojas Bermúdez iniciou o ensino e a formação em Psicodrama em São Paulo e participamos dessa pioneira formação. A seguir, convidamos o Dr. Soeiro, que também fazia parte do grupo de formação com o Dr. Bermúdez, a vir ao Serviço de Psicoterapia e juntos organizamos um grupo pioneiro. Desse grupo saiu o primeiro trabalho sobre Psicodrama no Instituto de Psiquiatria, relatando a experiência psicodramática daquele grupo inicial e a primeira aplicação do Psicodrama nesse Instituto. Publicamos também, na ocasião, um trabalho pioneiro sobre Role Playing em estudantes de Medicina no ensino da relação médico-paciente.

Após 1968, o Serviço de Psicoterapia havia produzido, na área de pesquisa, trabalhos em Psicoterapia de base psicanalítica e base psicodramática. Quanto ao serviço assistencial, devido ao número elevado de grupos, podíamos apresentar uma estatística de atendimento razoável. Na parte do ensino, promovíamos o treinamento de colegas menos experientes que passavam pelo Serviço de Psicoterapia. Eles eram colocados como observadores na sala dos espelhos, como observadores e anotadores dentro da sala de terapia e como supervisionando de seus casos clínicos.

Na década de 1970 o Serviço estava no seu apogeu, com colegas publicando artigos sobre Psicoterapia e os levando a congressos nacionais e internacionais. Eu mesmo, em 1972, defendi meu doutoramento com tema relacionado à Psicoterapia: Contribuição ao Estudo dos Abandonos em Psicoterapia de Grupo.

Nos períodos em que eu chefiava o Serviço, procurava estimular a inclusão de diversas correntes psicoterápicas no sentido de pesquisa e ensino. Observava que na década de 1970 os colegas estavam motivados, principalmente, para Psicoterapia de base psicanalítica e psicodramática. Queríamos que algum colega se dispusesse a organizar um grupo, no Serviço de Psicoterapia, a fim de pesquisar a então nova corrente chamada Análise Transacional. Convidamos o Dr. Roberto Kertez, membro da Associação Internacional de Análise Transacional, a promover um curso sobre o assunto, no sentido de estimular os colegas. Eu mesmo, em 1968, tive a oportunidade, no IV Congresso Internacional de Psicoterapia de Grupo, em Viena, de conversar pessoalmente com Eric Berne sobre a corrente que ele fundara: a Análise Transacional. Percebi o aspecto prático dessa técnica e estimulei colegas a experimentá-la, mas na ocasião ninguém se interessou. Procurei também estimular colegas a montar um grupo com a Terapia Comportamental (a Cognitivo-comportamental ainda não estava operando em nosso meio) e mais uma vez não encontrei colegas motivados. Isso fez com que na década de 1970 a Psicanálise e o Psicodrama ocupassem todo o espaço do Serviço. A seguir, felizmente, apareceram outros colegas promovendo outras formas de Psicoterapia, como foi o caso da Psicoterapia Junguiana, promovida pelo Dr. Nairo de Souza Vargas. 
Com o tempo, afastei-me do Serviço de Psicoterapia, trabalhando mais nas áreas do Conselho Departamental e do Conselho Diretor do Departamento de Psiquiatria da FMUSP, porém sempre observando com carinho o Serviço de Psicoterapia, que, liderado por excelentes colegas, se destacou como um Serviço muito respeitado em São Paulo, satisfazendo aquele meu antigo sonho de que o Serviço deveria ter todas as correntes para que o aluno pudesse escolher a que melhor lhe conviesse.

Nesses últimos anos, felizmente, a Terapia Cognitivo-comportamental passou também a fazer parte do arsenal do Serviço de Psicoterapia, liderada pelo Prof. Dr. Francisco Lotufo Neto, que tem organizado simpósios e congressos sobre o tema.

Assim, hoje o Serviço de Psicoterapia tem condições de oferecer especialistas na área de Psicoterapia Psicanalítica, Análise Junguiana, Psicoterapia Psicodramática, Terapia Cognitivo-comportamental, Psicoterapia breve etc. Com o arsenal técnico e teórico atual e com esses colegas especializados, esse Serviço é digno de pertencer ao tradicional Instituto de Psiquiatria A. C. Pacheco e Silva.

Em 1967, Fernando de Oliveira Bastos, assumindo a Cadeira, contribuiu ativamente para continuar o trabalho de Pacheco e Silva, estimulando novos livresdocentes e doutores. No período de sua gestão, Eneida Baptistete Matarazzo, eu e outros defendemos a nossa livre-docência: Eneida, com a tese Psicose Epiléptica na Infância e na Adolescência - 1977; eu, com a tese Contribuição para o Estudo Semiológico do Sinal da Linha - 1975; Resende de Lima, com a tese Correlações entre Intensidades de Instintos e Psicoses Esquizofrênicas, Maníaco-Depressivas e Epilépticas - 1974; Públio Salles Silva, com a tese Alguns Aspectos da Epilepsia Temporal - 1974; e Sidney Aparecido Chioro, com a tese Contribuição para o Estudo dos Distúrbios Emocionais e do Comportamento na Dislexia Específica de Evolução - 1975.

O Prof. Fernando de Oliveira Bastos, com grande experiência psiquiátrica e com um temperamento muito afável, estimulou seus assistentes a seguir carreira universitária. Fernando de Oliveira Bastos contribuiu para formar novos docentes, para remodelar o ensino de graduação e ampliar o número de residentes. Em 1972, fundou a Revista de Psiquiatria Clínica e, na sua qualidade de diretor científico do periódico, participou ativamente no trabalho redatorial. É importante que se diga que a nossa Revista de Psiquiatria, agora com 30 anos de existência, nasceu em 1962 com o nome de Boletim Bibliográfico, sob a responsabilidade de Clóvis Martins. Inicialmente, muito modesta com a análise de livros novos, resumos de conferências e relação de livros novos doados. Em 1963, Clóvis Martins transformou o
Boletim Bibliográfico em Boletim de Psiquiatria, quando então trabalhos originais foram apresentados, notícias de congressos etc. Clóvis Martins esforçava-se para dar continuidade àquele boletim, apresentado em papel mimeografado. Em 1972, o Boletim de Psiquiatria transformou-se em Revista de Psiquiatria, sob a direção de Antonio Carlos Pacheco e Silva, Fernando de Oliveira Bastos, João Carvalhal Ribas e José Roberto de Albuquerque Fortes. Walter Nelson Cardo figurou oficialmente, por longos anos, como co-editor da Revista de Psiquiatria Clínica, porém era quem realmente a administrava. O nosso atual CEIP (Centro de Estudos do Instituto de Psiquiatria), fundado em 1980, teve em Walter Nelson Cardo um dos seus fundadores e que também participou da primeira diretoria.

O Prof. Bastos prestigiou muito a implantação da pós-graduação. Infelizmente teve que se afastar da Cadeira de Psiquiatria por motivo de doença, sendo substituído na regência pelo Prof. João Carvalhal Ribas.

Como sabemos através da história da civilização, os jovens atenienses, ao receber suas armas para defesa da pátria, eram obrigados a prestar um juramento que deveria ser lembrado pela sua juventude: "Combaterei por tudo quanto for santo e sagrado. Não entregarei, aos que me sucederam, uma pátria menor do que a que recebi, mas maior e mais forte". Pacheco e Silva e Fernando Bastos saíram e entregaram um Departamento cada vez mais fortalecido. O Prof. Carvalhal Ribas assumiu como Professor Titular Substituto o Departamento de Neuropsiquiatria da Faculdade de Medicina da USP de novembro de 1976 a agosto de 1978, em substituição ao Prof. Bastos.

Após a era Bastos, outros colegas defenderam sua livre-docência: Zacaria Borge Ali Ramadam (com a tese Psicoses vinculadas: estruturas psicopatológicas inaparentes - 1979), Cacilda Cuba dos Santos (com a tese Psicoterapia Junguiana de Crianças e Pré-adolescentes: Contribuição para o Estudo de seus Fundamentos - 1982) e Valentim Gentil Filho (com a tese Contribuição para o Estudo de Funções Cerebrais Superiores a partir dos Efeitos de um Benzodiazepínico e seus Antagonistas em Voluntários Normais - 1987). Com a aposentadoria do Prof. Bastos, em 1978, deixou de haver Professor Titular Efetivo a ser substituído pelo Professor Adjunto, que no caso era o Prof. Carvalhal Ribas. Como o Instituto de Psiquiatria só pode ser dirigido por Professor Titular Efetivo, de acordo com o regulamento do Hospital das Clínicas, o Conselho Deliberativo do Hospital das Clínicas indicou o Professor de Neurologia A. F. B. Lefèvre, Titular Efetivo do então Departamento de Neuropsiquiatria, para assumir o cargo de Diretor do Instituto de Psiquiatria. Nessas condições, o Prof. Carvalhal Ribas voltou a 
exercer suas funções de Professor Adjunto. O Professor Lefèvre, além de possuir grande talento e o respeito de todos os colegas, era de uma gentileza ímpar no trato. Ele muito contribuiu nessa fase transitória. Nesse período, o Prof. Zacaria Borge Ali Ramadam defende a sua livredocência (com a tese Psicoses Vinculadas: Estruturas Psicopatológicas Inaparentes - 1979), enriquecendo o corpo docente. Em maio de 1981, foi aberto o concurso para Professor Titular de Psiquiatria Clínica no Departamento de Neuropsiquiatria da FMUSP. Os candidatos inscritos foram os Profs. Drs. João Carvalhal Ribas e Clóvis Martins. O Prof. João Carvalhal Ribas foi indicado unanimemente como vencedor pela comissão julgadora, assumindo o cargo em julho de 1981.

O Prof. Carvalhal Ribas apresentava uma sólida base aliada a uma erudição admirável. A pedido do Prof. Pacheco e Silva foi, com Eneida Baptistete Matarazzo, responsável pela criação da disciplina de Psiquiatria Infantil na Divisão de Psiquiatria do Departamento de Neuropsiquiatria da Faculdade de Medicina da USP. Procurava estimular os diferentes setores da Clínica Psiquiátrica, bem como o desenvolvimento dos estudos de psicodinâmica. $\mathrm{O}$ seu sonho era ter um centro de formação em Psicoterapia. Carvalhal Ribas, além de ser um professor competente e erudito, não media esforços para motivar e ajudar seus companheiros de trabalho a subir os degraus da carreira universitária. Em sua casa, à noite, recebia colegas e os instruía na metodologia de pesquisa, na orientação da literatura etc. Possuía uma biblioteca fantástica. Eu, pessoalmente, fui um entre as dezenas de colegas a quem ele, incansavelmente, fornecia a sua experiência e o seu saber. Os professores do "primeiro escalão" de docentes, representados por Pacheco e Silva, Fernando Bastos, Carvalhal Ribas, Albuquerque Fortes, Jayme Gonçalves, Clóvis Martins e Henrique Marques de Carvalho, muito contribuíram para fornecer seu saber e sua experiência aos docentes do "segundo escalão" que ia se formando. Eu e os professores Oscar Rezende de Lima, Eneida Baptistete Matarazzo e Paulo Vaz de Arruda, em 1976, submetemonos ao concurso para Professor-Assistente Efetivo no Departamento de Psiquiatria da Faculdade de Medicina da USP. Fomos aprovados, engrossando o então "segundo escalão". Em 1979, após sua livre-docência, o Prof. Zacaria Borge Ali Ramadam veio juntar-se a esse grupo.

Em 1984, com a aposentadoria do Prof. Carvalhal Ribas, foi aberto concurso para novo Titular, cujos candidatos foram os Profs. Drs. José Roberto de Albuquerque Fortes, Oscar Rezende de Lima e Eneida Baptistete Matarazzo. A banca examinadora indicou o nome do Prof. Dr. José Roberto de Albuquerque Fortes, que foi o Titular da Cadeira até a sua aposentadoria compulsória. O Prof. Fortes, ao assumir em 1984 a Cadeira de Psiquiatria e a presidência do Conselho Diretor do Instituto de Psiquiatria, encontrou-o em fase de transformação: os médicos se reuniram em equipes e procuravam formar grupos especializados com finalidades assistenciais, didáticas e de pesquisa. O grande mérito do Prof. Fortes foi não só permitir o crescimento desses grupos como encorajá-los ao desenvolvimento. Assim, surgia o Grupo Interdisciplinar de Estudos do Alcoolismo e Farmacodependências (GREA), o Grupo de Estudos de Doenças Afetivas (GRUDA), o Ambulatório de Estudo da Ansiedade (AMBAN), o Projeto Esquizofrenia (PROJESQ), o Ambulatório de Bulimia e Outros Transtornos Alimentares (AMBULIM) etc.

O Conselho Diretor, em 1987, na gestão do Prof. Fortes, aprovou a construção de mais duas alas no quarto andar do Instituto de Psiquiatria com a intenção de instalar nova enfermaria e um centro de convivência. A Profa. Eneida Baptistete Matarazzo foi quem assumiu a liderança para a construção dessas alas. O Prof. Fortes estimulou que vários colegas fossem ao exterior buscar novos conhecimentos e modelos, quer nos Estados Unidos quer na Inglaterra, e alguns deles realizaram estágios de aperfeiçoamento no Maudsley Hospital da Universidade de Londres.

A França, antigo berço influenciador do Departamento de Psiquiatria, estava sendo substituída pelos Estados Unidos e pela Inglaterra.

Os modelos de enfoque e validação de artigos científicos foram mudando sob essa influência e também em virtude da mudança nos parâmetros internacionais advindos dos novos avanços da Psiquiatria.

Com a aposentadoria compulsória do Prof. Fortes, abriu-se uma vaga para novo Titular. Nos dias 22 e 23 de agosto de 1994, por meio de memorável concurso, o Prof. Valentim Gentil Filho tornou-se Professor Titular do Departamento de Psiquiatria da FMUSP. Os dois candidatos inscritos, os Profs. Drs. Valentim Gentil Filho e Zacaria Borge Ali Ramadam, demonstraram as suas competências e ambos abrilhantaram o concurso, dando à Faculdade de Medicina uma demonstração de espírito democrático e de pujança de seus componentes.

O Prof. Valentim, já anteriormente ao concurso para Titular, em 1992, como Chefe do Departamento, iniciou o que chamou, na ocasião, de desafios e oportunidades para reestruturar o ensino, a pesquisa e a assistência com referenciais modernos.

Valentim propunha organizar um plano diretor para transformações radicais do Instituto e de seus modelos de atendimento psiquiátrico.

Organizou um grupo de colegas, do qual somente no início fiz parte, para colocar no papel a futura reestruturação do Instituto de Psiquiatria. Pretendia 
Valentim modificar e reestruturar todo o edifício do Instituto de Psiquiatria, que, na ocasião, além de obsoleto para os padrões atuais, estava apodrecendo (encanamentos, aparelhagens ineficientes, sistema elétrico obsoleto e falido etc.). Planejava também reestruturar os padrões de enfermaria e agrupamento de pacientes de acordo com a moderna Psiquiatria que ele havia visto em outros países, como Inglaterra, Estados Unidos etc. Para isso teria que organizar uma força-tarefa, construir uma planta de acordo com os modelos modernos, submeter todo esse estudo aos peritos e pesquisadores sobre o assunto tanto nacionais como internacionais, conseguir verbas astronômicas, quebrar a resistência política e governamental que ia a favor do fechamento de grandes hospitais psiquiátricos e um enorme número de outras dificuldades.

Eu pensava comigo, silenciosamente, sem que ele soubesse: "este moço é um idealista romântico e não vai conseguir sair do plano teórico". Com o tempo, fiquei feliz com o seu sucesso, pois venceu todas essas dificuldades e, agora, no jubileu dos 50 anos do Instituto, esse plano não está mais no papel, mas sim em ação, pois metade do prédio do Instituto já está em plena reforma e Valentim luta para conseguir novas verbas para o acabamento. Depois de pronto, o Instituto poderá ser comparado aos melhores hospitais psiquiátricos do mundo, e tudo isso devido ao espírito idealista de um jovem que não se conformava em apenas acomodar-se com o cargo de Titular da Cadeira de Psiquiatria, mas sim transformá-la. Após a posse da Cadeira de Psiquiatria em 1994, já no cargo de Presidente do Conselho Diretor, acelerou esse plano diretor. O Prof. Valentim iniciou suas atividades no Instituto de Psiquiatria como uma locomotiva a todo vapor, esperando que seus colegas o seguissem no mesmo ritmo de velocidade no sentido de aperfeiçoar o Departamento e o Instituto de Psiquiatria.

Nos dias 26 e 27 de fevereiro de 1996, o Prof. Wagner Farid Gattaz, por meio de memorável concurso, elevou-se Professor Titular do Departamento de Psiquiatria da FMUSP. Um resumo de sua vida e trajetória profissional foi por nós publicado em artigo na Revista de Psiquiatria Clínica do Instituto de Psiquiatria. O Prof. Gattaz permaneceu 18 anos na Alemanha, tornando-se Professor de Psiquiatria no Instituto Central de Saúde Mental da Faculdade de Medicina de Mannheim da Universidade de Heidelberg. Como sabemos, Heidelberg é considerada o berço da Psiquiatria alemã. Por ela passaram os três psiquiatras que muito influenciaram este século: E. Kraepelin, K. Jaspers e K. Schneider.

O Prof. Gattaz inicia sua gestão como Titular de Psiquiatria da Faculdade de Medicina da USP aos 45 anos, com toda a vitalidade, maturidade e enorme acervo de conhecimentos e experiências trazidas da Alemanha.
O Prof. Gattaz, logo no início de sua gestão, apresentou projetos de pesquisa, que, com os projetos já existentes no Departamento de Psiquiatria, aceleraram o desenvolvimento a níveis de excelência.

Como vimos, o Prof. Pacheco e Silva muito lutou para o estudo das bases bioquímicas dos transtornos mentais. Gattaz, com suas pesquisas na Alemanha, trouxe para o Brasil o que há de mais moderno nessas pesquisas e organizou o LIM 27 nessa direção. Devemos lembrar que, quando estava na Alemanha, o Prof. Gattaz foi incluído no livro Os Melhores Pesquisadores Médicos da Alemanha e que, de 1980 até 1993, obteve 357 citações de seus trabalhos de pesquisa na literatura científica internacional, segundo dados do Institute for Scientific Information da Filadélfia, EUA.

A inclusão do Prof. Gattaz no Departamento de Psiquiatria da FMUSP aumentou sensivelmente o acervo de experiências e conhecimentos adquiridos nessa instituição.

Na década de 1990 um razoável número de livresdocentes foi conquistado pelo Instituto de Psiquiatria e pelo Departamento de Psiquiatria: Carmita Helena Najjar Abdo, em 1992, com a tese Interações Iatropatogênicas: uma Contribuição ao Estudo da Psicologia Médica; Francisco Baptista Assumpção Junior, em 1993, defende a tese Autismo Infantil: um Algoritmo Clínico; Hélio Elkis, em 1996, defende a tese Contribuição para o Estudo da Estrutura Psicopatológica Multifatorial da Esquizofrenia; em 1997, Francisco Lotufo Neto e Arthur Guerra de Andrade defendem suas teses, respectivamente, Psiquiatria e Religião A Prevalência de Transtornos Mentais entre Ministros Religiosos e Consumo de Drogas entre Alunos da Universidade de São Paulo; em 1998, Homero Pinto Valada defende a tese Estudos de Genética Molecular no Transtorno Afetivo Bipolar.

O nível dos candidatos à livre-docência em Psiquiatria no Departamento de Psiquiatria da FMUSP vem se elevando no sentido do grande acervo de conhecimentos, de trabalhos publicados, nacionais e internacionais, e do número de citações internacionais de seus artigos, demonstrando grande prestígio internacional. Podemos citar a última defesa de tese de livredocência, no Departamento de Psiquiatria da FMUSP, em agosto de 2002, pelo Dr. Geraldo Busatto. Geraldo, formado pela FMUSP, em 1987, foi residente no IPq e, posteriormente, médico colaborador até janeiro de 1991. A seguir, foi para Londres, onde realizou curso de Ph.D. no Departamento de Psicologia Médica do Instituto de Psiquiatria da Universidade de Londres de abril de 1991 a agosto de 1995. A seguir, permaneceu em Londres, como psiquiatra pesquisador, até 
setembro de 1996. Durante o seu período de trabalho no exterior, participou de muitos projetos multidisciplinares de pesquisa, entre eles a aplicação de técnicas de neuroimagem a estudos sobre a fisiologia e o tratamento dos transtornos mentais. Voltando ao Brasil, com toda essa bagagem, foi rapidamente aproveitado pelo nosso Departamento de Psiquiatria e permaneceu como médico pesquisador financiado pela FAPESP; a seguir, a partir de 2000, passou a ocupar o cargo de Docente no Departamento de Psiquiatria da FMUSP. Busatto continuou suas pesquisas no Brasil, porém sempre mantendo vínculos com a Universidade de Londres. Seus artigos científicos foram citados em um total de 389 vezes dentro do banco de dados do Science Citation Index (SCI) do Institute of Scientific Information. Ao defender sua livre-docência, em agosto de 2002, Busatto foi muito homenageado pela banca examinadora em virtude de seus méritos de pesquisador.

No passado, éramos discípulos das produções científicas da França. Posteriormente, discípulos da Europa e dos Estados Unidos. Atualmente, estamos no caminho de irmandade, de colegas que interagem. O próprio Instituto de Psiquiatria, com sua remodelação arquitetônica e funcional promovida pelo Prof. Valentim, já está colocado em níveis internacionais. Atualmente, o Prof. Gattaz, o Prof. Valentim e um corpo docente solidamente especializado concedem a esse Departamento e ao Instituto de Psiquiatria um local admirável, muito confiável e de excelência para o exercício, a pesquisa e o aprendizado da Psiquiatria.

O passado e sua recordação são muito importantes para a história, pois quem não conhece a história irá repeti-la, perdendo todas as experiências positivas e negativas e começando do zero, como se não houvesse um passado. $O$ passado, o presente e a perspectiva futura devem ser sempre integrados para que possamos ter uma visão mais abrangente do mundo e da conduta. Sei que não consegui sintetizar tudo sobre o passado do Instituto de Psiquiatria e do Departamento de Psiquiatria, porém dei o máximo do que minha cabeça foi capaz.

E o presente no Instituto de Psiquiatria e no Departamento de Psiquiatria da FMUSP?

É também um esforço muito grande sintetizar tudo o que se faz, hoje, no Instituto de Psiquiatria da FMUSP. Ao tentá-lo, procurei obter dados dos próprios responsáveis pelos serviços e setores. Admito que não pude ter todos os dados do que atualmente é feito no Instituto de Psiquiatria da FMUSP, porém apenas algumas informações para que outros setores do Brasil possam ter alguma idéia da enorme produção dessa Instituição.

\section{LIM 27 (Laboratório de Neurociências)}

Sob a coordenação de Wagner F. Gattaz e com a participação de Orestes Forlenza, Homero P. Vallada e Luis Basile, o LIM 27 foi estruturado e aparelhado graças a uma verba da FAPESP de cerca de um milhão e meio de dólares para um projeto temático: $\mathrm{O}$ metabolismo dos fosfolípides na esquizofrenia e também sobre a doença de Alzheimer.

O LIM 27 entrou em atividade no início de 1999. Sua fase inicial consistiu no treinamento e formação das equipes nas áreas de neuroquímica, genética, biologia molecular e neurofisiologia. Para isto foi fundamental a vinda de diversos cientistas estrangeiros para o laboratório, principalmente da Alemanha, atuaram no laboratório por períodos de 3 a 12 meses, durante os quais implantaram novos métodos de pesquisa e deram treinamento à equipe.

Em 2002, o laboratório teve um novo reforço com a contratação do Dr. Emanuel Dias Neto, que trouxe sua equipe do Instituto Ludwig (São Paulo) para dar novo impulso na área de genética molecular. Nos anos 2000 e 2001, o LIM 27 foi classificado com o 1음 lugar em produtividade científica entre os 62 LIMs do complexo do Hospital das Clínicas da FMUSP.

Os pesquisadores que trabalham no LIM 27, com seus artigos científicos e intercâmbio internacional, têm levado o Instituto de Psiquiatria da FMUSP a níveis de excelência. Wagner Gattaz, coordenador do LIM 27, já recebeu, até o momento, cerca de 1.494 citações internacionais (fonte: ISI - Institute for Scientific Information) relacionadas a seus artigos publicados, demonstrando que o Brasil, e especialmente o Instituto de Psiquiatria, recebe no exterior uma confirmação de seu atual status científico.

Recentemente, o Prof. Dr. Wagner Farid Gattaz passou a pertencer à Academia Brasileira de Ciências e, pelo que me consta, é o primeiro e único psiquiatra, no momento, convidado a pertencer a essa Academia.

Em 1997, Homero Pinto Vallada Filho tornou-se responsável pelo Módulo de Genética Molecular no Auxílio ao Projeto Temático submetido à FAPESP e sob coordenação do Prof. Wagner Gattaz. Em novembro de 1997, Homero Pinto Vallada e os professores José Eduardo Krieger e Maria Aparecida Nagai organizaram o laboratório virtual da FMUSP, participante do primeiro projeto genômico do Brasil.

Os resultados desse projeto foram publicados na revista Nature e cada pesquisador recebeu a Medalha do Mérito Científico e Tecnológico do Governo do Estado de São Paulo. 
Homero Pinto Vallada apresenta cerca de 800 citações sobre seus artigos, segundo o Institute for Scientific Information.

Mais informações sobre as pesquisas do LIM 27 podem ser obtidas peloe-mail gattaz@usp.br

\section{PROJESQ}

Em 1972, havia um grande debate conceitual sobre a esquizofrenia e um certo niilismo terapêutico.

Na década de 1980, com os trabalhos de Crow que separavam a esquizofrenia em subtipos e com o advento do conceito de sintomas positivos e negativos, houve um grande avanço, não só conceitual, como também maior sucesso terapêutico.

Nessa época, Hélio Elkis elaborava sua tese de doutorado sobre neuroimagem em alcoolismo, quando passou a se interessar pelos trabalhos da correlação entre alterações da neuroimagem estrutural do cérebro e sintomas psicopatológicos. Nesse momento, inicia suas pesquisas sobre essas correlações na esquizofrenia.

Após seu doutorado, decide ir para o exterior buscar o que de mais moderno havia no estudo da esquizofrenia, bem como juntar-se aos pesquisadores de lá. Primeiramente foi para o Instituto de Psiquiatria de Londres, por meio do convênio com o British Council, por um breve período. Quando solidificou seus conhecimentos, fechou o consultório, juntou toda a sua família e foi permanecer longo período fora do Brasil para atingir seus objetivos científicos. Foi para Cleveland, Ohio, EUA. Lá permaneceu por dois anos e meio em seu estágio de pós-doutorado em esquizofrenia e neuroimagem.

Após voltar do estágio, com sua bagagem sobre esquizofrenia bastante aumentada, resolveu fundar um grupo especializado de pesquisa e para isso convidou o Dr. Mário Rodrigues Louzã Neto, recém-doutorado na Alemanha, para juntos organizarem o PROJESQ. Após a fundação do Projeto Esquizofrenia - PROJESQ -, suas atividades se tornaram interligadas com o Departamento de Psiquiatria da Case Western Reserve University, em Cleveland, Ohio, EUA.

O PROJESQ e seus membros passaram a ter interligações internacionais, produzindo uma série de trabalhos apresentados nos principais congressos internacionais e, para se ter uma idéia do impacto desses trabalhos, basta apenas citar um de seus membros: o Prof. Dr. Hélio Elkis, que já recebeu cerca de 140 citações científicas internacionais de seus trabalhos.

Maiores informações sobre o PROJESQ poderão ser obtidas peloe-mail helkis@usp.br

\section{GREA - 2002}

Em 1979, Arthur Guerra de Andrade e Laura Helena S. Guerra de Andrade iniciaram as atividades do Grupo de Interconsultas, sistematizando os atendimentos psiquiátricos solicitados pelos outros institutos do Hospital das Clínicas e promovendo seguimento no atendimento hospitalar e orientação acadêmica para esses casos. Com o tempo, Arthur Guerra de Andrade passou a interessar-se pelos aspectos interdisciplinares de estudos de álcool e drogas, ficando na condução do Grupo de Interconsultas a Dra. Laura Helena S. Guerra de Andrade. O GREA (Grupo de Estudos de Alcoolismo) iniciou suas atividades em 1981, formado por residentes de Psiquiatria da FMUSP que consideravam insuficientes as informações presentes no curso de Medicina sobre o assunto. Esse grupo iniciou pesquisas, estudos e assistência sobre alcoolismo, crescendo em importância ao longo dos anos. Em 1987, o GREA fundiu-se com o GREF (Grupo de Estudos de Farmacodependências), que também era formado por residentes de Psiquiatria do HC da FMUSP. A partir dessa fusão, o grupo passou a ser denominado Grupo Interdisciplinar de Estudos de Álcool e Drogas, preservando a sigla GREA, mais conhecida.

Atualmente, o GREA desenvolve atividades nas áreas de pesquisa, ensino, assistência e prevenção relacionadas ao álcool, ao tabaco e a outras drogas. Nesse sentido, o grupo estimula o desenvolvimento de pesquisas e procura formar novos pesquisadores, incentivando a participação de alunos de graduação, pós-graduação e médicos residentes em projetos específicos do grupo. Essa preocupação é reconhecida por entidades como FAPESP e CNPq, que concedem bolsas de iniciação científica e auxílio-pesquisa. O trabalho é desenvolvido por uma equipe multidisciplinar composta por médicos psiquiatras, residentes de primeiro, segundo e terceiro anos, psicólogos, terapeutas ocupacionais e estagiários de Psicologia. O GREA é composto por quatro setores: administração, assistência, ensino e pesquisa, e prevenção.

Com uma atividade assistencial intensa no tratamento de diferentes grupos de dependentes, o projeto foi se expandindo e, em outubro de 1998, no prédio da Fundação Zerbini, unidade Frei Caneca, inaugurou-se uma nova unidade do GREA (Unidade Frei Caneca). Em setembro de 1999, o GREA ganhou uma unidade no prédio da administração da Escola Politécnica da USP, denominada GREA - Unidade Cidade Universitária, com a intenção de intensificar o trabalho de orientação e esclarecimento do Programa de Prevenção e Tratamento do Uso de Drogas na USP - PRODUSP, destinado a professores, alunos e funcionários da USP. 
As evidências epidemiológicas disponíveis sugerem um aumento do consumo de diversas substâncias, inclusive nas populações universitárias. Ciente dessa situação, a Secretaria Nacional Antidrogas (SENAD), representada pelo Centro de Integração Empresa-Escola (CIEE), vem promovendo a Campanha Nacional Antidrogas nas Escolas Superiores. Essa campanha foi delegada, na sua execução, ao GREA, com o apoio da Fundação Zerbini.

O imóvel Casa D. Yayá, após reforma e restauração, será utilizado para o Centro de Ensino a Distância na Área de Álcool e Drogas. AUSP, tendo recebido o imóvel em doação, conduziu o processo seletivo, que culminou na escolha do grupo Universidade e Cidadania, formado por GREA e PRODES. O objetivo dessa parceria, PRODES/GREA, é instalar no local um centro de informação, orientação e formação de agentes de prevenção ao uso indevido de álcool e outras drogas.

No ano de 2002, o Ministério da Saúde atribuiu a alguns centros de referência no tratamento e na pesquisa de dependências químicas, dentre eles o GREA, a responsabilidade de, com os gestores estaduais em saúde mental, implementar o programa permanente de capacitação para Rede de Centros de Atenção Psicossocial que atende pacientes com transtornos causados pelo consumo de substâncias psicoativas.

Dentro do GREA existe o PROMUD (Programa de Atenção à Mulher Dependente Química) e o AMJO (Ambulatório do Jogo Patológico e outros Transtornos do Impulso).

Em agosto de 2001, o Prof. Dr. Arthur Guerra de Andrade, que durante 20 anos exerceu a coordenação geral do GREA, passou-a a dois coordenadores executivos: a Dra. Sandra Scivoletto e o Dr. André Malbergier. Nessa mesma data, Arthur Guerra fundou o CTA - Conselho Técnico-Administrativo do GREA, órgão que norteia as macrorientações das atividades do GREA em termos de administração, assistência, prevenção, ensino e pesquisa.

O CTA é um órgão informal despido de personalidade jurídica, integrado por pessoas físicas identificadas por interesse convergente de emprestar apoio ao GREA. Atualmente o CTA é composto de ilustres membros de diferentes áreas da comunidade.

O GREA apresenta uma rede de vínculos nacionais e internacionais. Entre alguns vínculos nacionais, temos USP - Universidade de São Paulo, FAPESP - Fundação de Amparo à Pesquisa do Estado de São Paulo, $\mathrm{CNPq}-$ Conselho Nacional de Desenvolvimento Científico e Tecnológico, Fundação Zerbini, CIEE - Centro de Integração Empresa-Escola, SENAD - Secretaria Nacional Antidrogas, FFM - Fundação Faculdade de Medicina da
USP, CEIP - Centro de Estudos do Instituto de Psiquiatria, ABEAD - Associação Brasileira de Estudos de Álcool e outras Drogas, Associação Parceria contra Drogas.

Entre alguns vínculos internacionais, temos ICAA International Council on Alcohol and Addiction, The Partners of the Americas, UNDCP - United Nations International Drug Central Programme, The Johns Hopkins University Baltimore.

É praticamente muito difícil apontar todas as atividades do GREA, que é uma grande Instituição dentro do Instituto de Psiquiatria da FMUSP. O Prof. Arthur Guerra de Andrade, fundador, organizador e dirigente do GREA até agosto de 2001, prestigiou o nome do Instituto na área de prevenção e tratamento do alcoolismo e de dependentes de drogas. Recebeu várias homenagens, como diploma de mérito e medalhas pela sua atividade nesta área.

O prestígio do GREA fez com que recebesse valiosos recursos financeiros de projetos desenvolvidos em parceria com várias instituições, entre elas USP, FAPESP, CNPq, Fundação Zerbini, CIEE, Colégio Santo Américo, SENAD, Ministério da Saúde.

Para mais esclarecimentos podemos contatar os endereços: grea@edu.usp.brou aandrade@usp.br

\section{AMBAN}

Nas décadas de 1960 e 1970, os quadros clínicos que expressavam ansiedade, em geral, eram rotulados como neurose, e as crises de pânico eram consideradas uma intensificação da ansiedade em um quadro neurótico. A partir da década de 1980, o diagnóstico e a classificação dos transtornos ansiosos foram substancialmente revistos a partir da publicação da DSM-III. Os ataques de pânico são agora vistos como manifestação qualitativamente importante, e não apenas como uma intensidade maior de ansiedade.

Já na década de 1960, Donald Klein propunha que retornássemos às idéias de Freud de 1895. Freud justificou a separação da neurose de angústia da neurastenia. Nesse artigo ele separa os mecanismos etiológicos da angústia na neurose de angústia dos das psiconeuroses. Freud vinha chamando a atenção para determinados quadros neuróticos que pareciam não apresentar mecanismos psíquicos (como os das psiconeuroses) e chamou estes quadros de neuroses atuais. Na neurose atual haveria uma causa atual atuante e o sintoma de angústia não era expressão de um conflito intrapsíquico reprimido subjacente. Procurou explicar, naquela época, com a teoria de haver um aumento da quantidade de energia no interior do aparelho psíquico subjacente, energia esta que se traduziria pela angústia. 
Assim, dizia Freud: "A ansiedade, provavelmente correspondente a essa excitação acumulada, é de origem somática; e, além do mais, que essa excitação somática é de natureza sexual e ocorre paralelamente a um decréscimo da participação psíquica nos processos sexuais".

Em 1981, em um relato pioneiro, Gloger et al. apontaram para a eficácia de baixas doses de clomipramina no transtorno do pânico. Essa substância já era utilizada para transtornos depressivos, compulsivos, obsessivos e e ansiosos, porém, sempre em altas doses, com efeitos colaterais significativos e intolerância por parte dos pacientes mais ansiosos. As doses preconizadas por Gloger eram consideradas, na época, subterapêuticas mas revelaram-se eficazes também em nosso meio.

Valentim, ciente de todos esses novos posicionamentos, resolveu organizar um grupo de pesquisa e estudos sobre a ansiedade e tudo o que se refere a ela.

Devemos lembrar que atualmente pesquisadores do Grupo de Dor do Hospital das Clínicas da FMUSP vêm desenvolvendo pesquisas para tratamento e pesquisas sobre a dor. Estatísticas norte-americanas atribuem perdas anuais de 150 bilhões de dólares em virtude da existência da dor.

É interessante que se ressalve que eles se preocupam com a dor física. A ansiedade é dor psíquica e provocará problemas socioeconômicos tanto quanto a dor física.

Valentim já vislumbrava, na década de 1980, a importância de se pesquisar a dor psíquica, ou seja, a ansiedade.

Acumulada uma casuística privada com excelente resposta à clomipramina e tendo que verificar a validade crescente do volume de informações sobre diferentes aspectos relacionados com os transtornos ansiosos, Valentim organizou, sob os auspícios da Associação Fundo de Incentivo à Psicofarmacologia, um Encontro Multidisciplinar sobre Ansiedade Autonômica: Diagnóstico Diferencial e Bases Biológicas, em maio de 1984. Dele participaram 38 profissionais de diferentes áreas relacionadas ao tema.

Nesse encontro verificou-se que a casuística sobre o tema era reduzida e que seria oportuno comparar os efeitos da clomipramina aos da imipramina, então considerada padrão no tratamento de pânico. No Rio de Janeiro, outros pesquisadores participaram de ensaios clínicos comparando a administração de diazepínicos e da imipramina.

Valentim resolveu organizar o Projeto do Ambulatório de Ansiedade - AMBAN - com pessoas interessadas em pesquisa e entre elas vários pós-graduandos que posteriormente destacaram-se em suas vidas acadêmicas. Dentre os vários integrantes do Projeto AMBAN, lembramos alguns: Laura Helena S. G. Andrade, Francisco
Lotufo Neto, Márcio Bernik, Táki A. Cordás, Renato T. Ramos e Clarice Gorestein.

Valentim em suas observações propunha que questões científicas quanto à ansiedade deveriam ser pesquisadas e respondidas: Qual é a validade do conceito de pânico e qual a melhor forma de tratá-lo e quais as relações com outros diagnósticos psiquiátricos?

O projeto levou alguns anos para ter suas evidências científicas publicadas. Após essa primeira fase, agora sob a coordenação de Francisco Lotufo e Márcio Bernik, novos ensaios clínicos apontaram os efeitos a longo prazo da clomipramina. Hoje o AMBAN é um centro de excelência para a pesquisa da ansiedade e suas relações interdisciplinares. Desde o início do Projeto AMBAN numerosas teses e dissertações foram desenvolvidas oferecendo ao Departamento de Psiquiatria e ao Instituto de Psiquiatria novos mestres e doutores, bem como livres-docentes.

Uma linha de atuação que é considerada essencial no AMBAN é a formação e a qualificação de profissionais, tanto para a realização de pesquisas como para a utilização dos modernos recursos terapêuticos em Psiquiatria. Em 1998, foi criada a Liga de Ansiedade, que visa à aquisição da experiência do AMBAN pelos alunos da Faculdade de Medicina da USP e, a partir de 1999, para os alunos da Faculdade de Medicina do ABC. O AMBAN tem promovido muitos cursos de extensão universitária, simpósios de atualização, cursos de formação em terapia cognitiva comportamental etc. A atividade de pesquisa é direcionada a transtornos ansiosos: transtorno do pânico, transtorno obsessivo-compulsivo, fobias e transtornos sexuais. As pesquisas envolvem: diagnóstico, epidemiologia, fisiopatologia, psicopatologia, tratamento farmacológico e tratamento psicoterápico. Múltiplos projetos sobre os temas foram finalizados e outros estão em andamento. Os trabalhos realizados pelo grupo já geraram 83 publicações de artigos em revistas científicas, sendo 19 em revista de circulação internacional e 64 em revistas nacionais. $\mathrm{O}$ AMBAN tem publicado livros e capítulos de livros sobre a especialidade. Recebeu prêmios pelos seus trabalhos, como foi o prêmio Osvaldo Cruz e o prêmio Bristol. Mantém intercâmbio científico com Centros Universitários do exterior, tendo recebido, desde 1985, 12 pesquisadores estrangeiros que proferiram palestras, ministraram cursos e ofereceram supervisão a projetos de pesquisa.

Para mais informações:

bernikma@alternex.com.br

www.amban.org.br e

franciscolotufo@uol.com.br. 


\section{PROTOC}

O Projeto Transtornos do Espectro ObsessivoCompulsivo (PROTOC) foi criado em 1994 por Eurípides Constantino Miguel e Marcos T. Mercadante no sentido de desenvolver pesquisas e tratamento para os transtornos obsessivo-compulsivos (TOC) e também para a síndrome de Tourette (ST), os transtornos dismórficos corporais e a tricotilomania.

$\mathrm{O}$ estudo do transtorno obsessivo-compulsivo e da síndrome de Tourette constitui a principal área de interesse do PROTOC.

Eurípides e Mercadante constituíram um grupo de pesquisa que, desde 1994, vem promovendo o desenvolvimento do conhecimento sobre o assunto. Eurípides C. Miguel, Marcos T. Mercadante, Ana G. Hounie e muitos outros profissionais médicos, psicólogos, pósgraduandos etc. constituem hoje um grupo de pesquisadores que tem publicado artigos sobre o assunto em revistas nacionais e internacionais.

O PROTOC mantém cooperação científica com várias instituições nacionais e internacionais. Quanto às internacionais, temos a Universidade de Yale, a Universidade de Harvard, a Universidade Estadual de Nova York, a Universidade de Rockefeller e a Universidade de Brown. Quanto à cooperação com instituições Nacionais, temos Universidade Federal do Rio Grande do Sul, Pontifícia Universidade Católica do Rio Grande do Sul, Santa Casa de Misericórdia do Rio de Janeiro, Escola Paulista de Medicina, Faculdade de Medicina de Botucatu (Unesp) e Universidade Federal de Pernambuco (UFPE).

O Prof. James F. Leckman, diretor de pesquisa do Child Study Center da Universidade de Yale, tem colaborado com o PROTOC e publicado, com integrantes do PROTOC, numerosos artigos de interesse internacional. Entre essas publicações, a grande maioria apresenta Eurípides C. Miguel e Marcos T. Mercadante como seus autores ou co-autores.

Com a Universidade de Harvard, por intermédio do Prof. Michael Jenike, o PROTOC tem publicado em conjunto muitos artigos de interesse internacional sobre os temas.

Aqui, Eurípides C. Miguel destaca-se como o principal autor do PROTOC em número de publicações.

Ainda podemos citar o convênio com a Universidade de Harvard, por intermédio do Prof. David Pauls, no qual há um intercâmbio em pesquisas genéticas. Atualmente o Prof. David é co-orientador da Dra. Maria Conceição Rosário-Campos, que iniciou seu doutoradosanduíche na Universidade de Yale, e da Dra. Ana G. Hounie, que desenvolve seu doutorado no Brasil.
O convênio com a Universidade de Brown é feito por intermédio do Prof. Steve Rasmussen. No momento há um projeto de pesquisa sobre a radiocirurgia no transtorno obsessivo-compulsivo. Desse projeto deverá sair uma tese de doutorado de Antonio Carlos Lopes.

O PROTOC, desde a sua fundação até o momento, já publicou mais de 30 artigos internacionais de grande interesse para o desenvolvimento das pesquisas sobre os transtornos obsessivo-compulsivos e da síndrome de Tourette.

O PROTOC teve grande importância na criação da Associação de familiares e pacientes com transtornos obsessivo-compulsivos e síndrome de Tourette (ASTOC), com sede na mesma área física. Membros do PROTOC fazem parte do comitê científico da ASTOC. Ambos têm organizado inúmeros artigos nacionais e internacionais com o objetivo de levar informações atualizadas à comunidade. ASTOC e PROTOC colaboram com um projeto em conjunto com a Prefeitura do Município de São Paulo no sentido de atualização de profissionais de saúde mental contratados pela prefeitura. Esse programa inclui cursos e supervisão de casos. Eurípides e Mercadante são respectivamente editor e editor associado da Revista Brasileira de Psiquiatria, que se constituiu numa das principais revistas científicas nacionais.

A partir deste ano, o PROTOC faz parte do Consórcio Internacional sobre o Estudo da Genética do Transtorno Obsessivo-Compulsivo, patrocinado pela Obsessive Compulsive Foundation. Desse Consórcio fazem parte cerca de 30 Centros Internacionais. O PROTOC representando o Brasil e outro centro representando o México são os únicos participantes de países da América Latina. É importante assinalar que o PROTOC acusa 314 citações internacionais de seus artigos, sendo que, destas, 283 pertencem aos artigos de Eurípides C. Miguel (Coordenador Geral do PROTOC).

Contato para mais informações:

ecmiguel@usp.br

\section{Serviço de Psicologia}

Ao longo de seu funcionamento, o Serviço de Psicologia tem contado com um quadro de profissionais habilitados e qualificados nas mais importantes universidades e instituições do País, em nível de graduação, pós-graduação, especialização e formação de terapeutas, comprometidos com a assistência, o ensino e a pesquisa, na área médica e de saúde mental. Vários profissionais do Serviço, ao longo desses anos, defenderam teses de mestrado e doutorado. 
Como vimos no histórico do Serviço de Psicologia, as atribuições se limitavam a executar exames psicológicos, elaborando diagnósticos e relatórios (décadas de 1950 e 1960).

Com o passar dos anos, essa limitação foi superada e o Serviço pôde utilizar todo o real potencial dos psicólogos que ali trabalhavam. Atualmente, o Serviço é dirigido desde 1994 por Cândida Helena Pires de Camargo, que dirige uma equipe de mais de 100 pessoas entre as psicólogas oficialmente contratadas, as psicólogas estagiárias e as aprimorandas.

Atualmente o Serviço participa das comissões e dos grupos de estudos do Instituto, assim como na organização das equipes multiprofissionais, cujo trabalho vem sendo implementado até hoje. Atua com os grupos especiais, como por exemplo AMBAN, GREA, GRUDA, PROTER, Pró-Mulher e PROJESQ.

O Serviço de Psicologia no campo de atividades de assistência desenvolve atividades com pacientes encaminhados pelo corpo médico e procedentes da enfermaria ou do ambulatório.

Nas enfermarias desenvolve atividades terapêuticas grupais com os pacientes e seus familiares. Promove o atendimento psicoterápico aos pacientes encaminhados pelo Serviço de Psicoterapia do Instituto, bem como a funcionários e familiares destes. Em 1996, o Serviço de Psicologia desenvolveu a Brinquedoteca Terapêutica dentro do Serviço de Psiquiatria Infantil e do Adolescente do IPq, fortalecendo as mudanças qualitativas e quantitativas em relação às possibilidades de tratamento. Em 1997, o Serviço de Psicologia inseriu-se na equipe multiprofissional responsável pela implantação do hospitaldia infantil, que surgiu como uma proposta de atendimento pluridimensional e multiprofissional e inclui a avaliação diagnóstica e várias modalidades de tratamento médico, psiquiátrico, psicossocial e educacional. No ano de 2000, o Serviço participou do projeto de implantação de um sistema de saúde mental em Porto Nacional, Tocantins, em colaboração com médicos e outros profissionais da equipe multiprofissional.

Em 2001, o Serviço de Psicologia passou a integrar a equipe de profissionais que desenvolve o Programa de Atendimento Domiciliar (PRADO).

O Serviço de Psicologia, além das atribuições relativas à assistência, desenvolve programas de ensino na área voltados aos médicos residentes, psicólogos e profissionais da saúde.

O Curso de Aprimoramento de Psicologia Hospitalar em Instituição Psiquiátrica, destinado a psicólogos e a estudantes de Psicologia, foi, em 1995, transformado em curso de especialização aprovado pelo MEC, sob o nome de Curso de Especialização de Psicologia Hospitalar em Avaliação Psicológica e Neuropsicológica.

A atividade de pesquisa vem se caracterizando pelo desenvolvimento de pesquisas próprias do Serviço e também em colaboração com outros setores e profissionais pesquisadores do Instituto. O Serviço de Psicologia colabora e dá suporte a projetos de pesquisa e teses de doutoramento mediante elaboração de protocolos psicológicos e neuropsicológicos para estudo controlado de pacientes. Entre os grupos estudados, há usuários de drogas, crianças com transtornos afetivos, autismo, funções cognitivas em neurocisticercose, alcoolismo, idosos, esquizofrenia etc.

\section{Psicologia Médica}

Atualmente, o Curso de Psicologia Médica, dirigido por Arthur Kaufman, é constituído por aulas teóricas, seminários e dinâmica de grupo.

Nas aulas teóricas são abordados temas de Psicologia de grande importância dentro da Medicina, além de assuntos que privilegiam a relação médico-paciente. Em algumas aulas são utilizados filmes como instrumentos para facilitação do aprendizado. Nos seminários, em grupos de 15 alunos, são debatidos os ensaios, previamente preparados por escrito pelos estudantes, a respeito de temas relacionados à figura do estudante, do médico e da prática médica. Durante a dinâmica de grupo, auxiliados pelas técnicas psicológicas grupais, os alunos podem aprofundar várias questões referentes à figura do médico, à prática médica e à relação médicopaciente. Como são muitos os alunos e, portanto, vários grupos, a técnica grupal será diferente de acordo com a orientação dos docentes (orientação psicanalítica, psicodramática junguiana etc.)

\section{O Serviço de Psicoterapia}

O Serviço de Psicoterapia é dirigido pelo psicanalista Oswaldo Ferreira Leite Netto, que tem dado a esse Serviço um alargamento de suas atividades. Aqui estão profissionais de alta qualificação em diferentes correntes psicoterápicas, como Psicanálise, Análise Junguiana, Psicodrama, Terapia Cognitivo-Comportamental etc.

Nos últimos anos, o Serviço vem se desdobrando internamente: foi criado o Grupo de Psicoterapia Dinâmica Breve e lá funciona o Projeto Sexualidade (ProSex), que atende, multidisciplinarmente, pacientes com problemas na esfera da sexualidade. Há também o Projeto de Atendimento ao Obeso (PRATO) e o Gender Group, para psicoterapia psicodinâmica grupal, de homens e 
mulheres, focando os problemas relacionados à identidade de gênero, masculino e feminino.

Os médicos assistentes do Serviço de Psicoterapia passaram a participar das equipes dos ambulatórios, com a função específica de supervisionar aspectos psicológicos envolvidos no diagnóstico e no atendimento dos pacientes psiquiátricos, independentemente da indicação ou não de psicoterapia. Supervisões psicodinâmicas também são exercidas por assistentes do Serviço nas enfermarias, destinadas aos residentes, sobretudo quanto ao atendimento de familiares.

Os assistentes do Serviço de Psicoterapia atualmente participam como tutores dos residentes em Psiquiatria. Na Faculdade de Medicina existe o Projeto Tutor que abrange 1.060 alunos da Faculdade de Medicina da USP e que foi implantado em 2001. Do Serviço de Psicoterapia participa Oswaldo Ferreira Leite, bem como outros colegas do Serviço - a exemplo de Nairo de Souza Vargas -, como membro supervisor e membro da Comissão Técnica do Projeto Tutor.

A disciplina Bases Humanísticas da Medicina também recebe do Serviço de Psicoterapia professores especializados que contribuem para o curso.

\section{A enfermagem do IPq hoje}

Hoje, o treinamento e a ampliação dos conhecimentos da equipe de enfermagem passaram a ser prioritários e a ocorrer em vários momentos, em cursos formais e informais. Tornou-se política da instituição estimular e oferecer oportunidades, em termos de horas, para que os enfermeiros fizessem pós-graduação, em nível de mestrado e doutorado. Em 2001, dando sequiência a essa atividade de atualização, foi criado o grupo de pesquisa científica, supervisionado pela Profa. Dra. Maguida Costa Stefanelli, com o objetivo de realizar pesquisas de enfermagem dentro do Instituto de Psiquiatria. Em 1997, o grupo de enfermeiros baseado em sua prática escreveu e lançou o livro intitulado Manual de Enfermagem Psiquiátrica, que serve de embasamento para a assistência oferecida na Divisão de Enfermagem. Os enfermeiros do IPq acompanham os diferentes grupos de estudos e projetos criados no IPq, como GREA, GRUDA, AMBAN, AMBULIM, PROJESQ, PROTER, PROTOC, ProSex, PRATO, entre outros, bem como os laboratórios de pesquisa, destacando-se o de Psicofarmacologia e Psicofisiologia Clínica e de Neurociências (LIMs 23 e 27).

Nesses últimos anos, os enfermeiros têm procurado seu aprimoramento fazendo diversos cursos, como os cursos de especialização em enfermagem psiquiátrica e também o de terapia cognitivo-comportamental, oferecidos pelo IPq.
Nos últimos anos a produção científica dos enfermeiros do IPq tem crescido qualitativa e quantitativamente, com efetiva participação em eventos nacionais e internacionais, tendo já recebido prêmio internacional. Esses fatos ressaltam a importância da criação do Grupo de Estudos e Pesquisa em Enfermagem e Saúde Mental, no início de 2001, pela enfermeira e Profa. Titular Dra. Maguida Costa Stefanelli. Cabe destacar que a pesquisa em enfermagem no IPq vem se desenvolvendo há duas décadas. Na última década, com a contratação da enfermeira Marina Borges Teixeira, com Doutorado em Enfermagem, e, posteriormente, de Maguida Costa Stefanelli, a pesquisa e o ensino tiveram seu ritmo acelerado.

As tendências atuais da Enfermagem no IPq evoluem para a especialização de enfermagem psiquiátrica, engajamento do enfermeiro em trabalho multidisciplinar em grupos de estudos, integração de enfermeiros por unidades de trabalho segundo sua competência e afinidade, desenvolvimento de linhas de pesquisa de acordo com a opção de trabalho, elaboração e seguimento do quadro de projeção dos enfermeiros, intercâmbio científico com enfermeiros do exterior, especificamente de Pittsburg e Londres, dois dos Centros mais avançados na assistência psiquiátrica, que mantêm intercâmbio com o IPq.

\section{O Serviço Social}

Atualmente, o Serviço Social tem um amplo campo de ação. Suas atividades no ensino, na assistência e na pesquisa se alargaram. Na assistência promove procedimentos imediatos e de emergência social, atendimento individual informativo-educativo, atendimento terapêutico, atendimento socializador, grupo informativo-educativo, grupo terapêutico, grupo socializador, terapia familiar, visita domiciliar, atuação preventiva etc. Quanto ao ensino e à pesquisa, o Serviço Social promove programa de aprimoramento profissional, programa de supervisão, programa de educação continuada, intercâmbio do Serviço Social com USP/Unesp/Unicamp, grupo de estudos de Teoria do Serviço Social, grupo de estudos de Teorias de Saúde Mental etc.

O Serviço Social, em relação à comunidade, promove cadastro, atualização e informatização de recursos médicos sociais, acompanhamento terapêutico, assistência domiciliar etc.

Nas unidades de internação e centro de reabilitação e hospital-dia, o Serviço Social promove grupos com diferentes finalidades, como por exemplo Grupo Psicoeducacional, Grupo de Familiares, Grupo de Cidadania etc.

Tem participação ativa nos grupos especializados, como PROJES, AMBAN, AMBULIM, TOC etc. 
Tem promovido aos assistentes sociais a oportunidade de desenvolver suas teses de mestrado e doutorado.

\section{A Terapia Ocupacional}

Hoje, a Terapia Ocupacional tem seu campo de ação ampliado e está bem diferente do que foi no tempo de Tazuro Moriyama.

Em 1990 houve uma reestruturação e a Terapia Ocupacional iniciou o atendimento ambulatorial de retaguarda, o que implicou também a reestruturação do quadro de profissionais. Com a ampliação dos atendimentos do Serviço de Terapia Ocupacional, não só em nível ambulatorial, mas também de enfermaria e grupos específicos, constatou-se que os pacientes apresentavam queixas referentes à rotina diária, pois passavam seus dias de forma ociosa, deitados ou sentados diante da TV. A equipe de Terapia Ocupacional promoveu um espaço onde o paciente pudesse ter uma vivência prática, constante e diária de atividades dirigidas e estruturadas. A equipe concluiu que essas atividades deveriam ser semelhantes àquelas que os pacientes pudessem se ocupar em suas casas após a saída do hospital. Surgiram em 1992 as primeiras oficinas terapêuticas: artesanatos, bijouterias etc.

Em 1994, mais duas oficinas terapêuticas foram criadas: culinária e encadernação. A seguir, a criação da "lanchonete", onde pacientes atendiam ao público (funcionários e pacientes do IPq). Em 1997, teve início o Curso de Aprimoramento de Terapia Ocupacional em Saúde Mental. Estabelece-se um campo de estágio curricular para alunos de graduação dos cursos de Terapia Ocupacional (USP, UFSCar e outras).

Em julho de 1999 foi aprovada a pesquisa, pela Comissão de Ética do Instituto de Psiquiatria da FMUSP, A Intervenção da Terapia Ocupacional em Pacientes Esquizofrênicos Refratários ao Tratamento PsicoFarmacológico, desenvolvida pelas Terapeutas Ocupacionais Adriana Dias Barbosa Vizzotto e Patrícia Cardoso Buchain, sob a orientação do Prof. Dr. Hélio Elkis.

Em 2000, formou-se o GRITO (Grupo Interagi T.O.), com a proposta de atuação intra e extra-hospitalar e objetivo futuro de criação de uma cooperativa com a comunidade.

No decorrer desses anos, a Terapia Ocupacional vem atuando com as unidades de internação, ambulatórios, hospital-dia infantil e adulto, bem como em grupos especializados como GREA, PROJESQ, ProSex, AMBULIM etc.

\section{LIM 23}

O LIM 23 (Laboratório de Psicofarmacologia e Psicopatologia Experimental e Terapêutica Psiquiátrica) originou-se do Grupo Multidisciplinar de Psicofisiologia Clínica, formado por profissionais do Departamento de Farmacologia do Instituto de Ciências Biomédicas da USP e do Instituto de Psiquiatria do Hospital das Clínicas da FMUSP, com o objetivo de desenvolver pesquisas sobre os efeitos de psicofármacos em voluntários normais.

Os primeiros estudos enfocaram os efeitos psicomotores e cognitivos agudos de benzodiazepínicos e antagonistas em voluntários normais, que resultaram em tese de doutorado (Profa. Dra. Clarice Gorenstein), em tese de livre-docência (Prof. Dr. Valentim Gentil) e em vários artigos publicados em revistas científicas.

Posteriormente, com a finalidade de conduzir estudos em pacientes psiquiátricos, o grupo foi ampliado e seu primeiro estudo foi sobre a síndrome do pânico no Ambulatório de Ansiedade (AMBAN): Projeto AMBAN - um Estudo Multidisciplinar sobre a Ansiedade, Envolvendo Aspectos Fisiopatológicos, Epidemiológicos, Diagnósticos e Terapêuticos. Esse projeto inspirou-se na experiência clínica do Prof. Valentim Gentil, cuja casuística demonstrava a validade do tratamento de pacientes com pânico/agorafobia com doses baixas de clomipramina. Esse estudo resultou em vários trabalhos publicados, teses (Profs. Drs. Francisco Lotufo Neto, Laura H. G. Andrade, Márcio Bernik, Renato T. Ramos, Tânia Marcourakis, além de dissertações de mestrado (Drs. Lúcia M. S. Maciel, Miréia Roso, Roseli G. Shavitt, Táki A. Cordás, Tânia Marcourakis). Dois membros da equipe realizaram seu doutoramento no exterior (Profa. Dra. Lígia M. Ito e Luiz Armando Araújo). Além das teses, foram publicados vários artigos científicos no livro Pânico, Fobias e Obsessões (EDUSP, 1994).

A infra-estrutura para desenvolvimento dessas atividades foi criada com verbas provenientes de doações de empresas e auxílio-pesquisa da FAPESP.

Em 1990, foi ativado o Laboratório de Psicofarmacologia, Psicopatologia Experimental e Terapêutica Psiquiátrica, LIM 23, sob a responsabilidade do Prof. Dr. Valentim Gentil, com a finalidade de desenvolver projetos de pesquisa desvinculados dos ambulatórios assistenciais, porém em contínua colaboração com estes em função dos estudos realizados.

O LIM 23 fornece infra-estrutura e coordena as atividades de pós-graduandos, docentes desta e de outras unidades da USP e pesquisadores colaboradores recémdoutorados no Brasil e no exterior. Desde a sua criação, o LIM 23 tem desenvolvido pesquisas em várias áreas, algumas em colaboração com profissionais de outros Centros nacionais e internacionais. Oferece infra-estrutura operacional para o Centro Brasileiro do Sistema PSE/CATEGO/SCAN, centro colaborador da Organização Mundial da Saúde que realiza pesquisas e oferece cursos regulares de treinamento. 
As linhas de pesquisa são abrangentes: Psicometria, Psicofisiologia, Psicofarmacologia, Psicopatologia, Terapia Cognitivo-Comportamental, PSE/Centro da OMS, Epidemiologia Psiquiátrica, Hematologia, Neuroimagem Funcional, Ansiedade e Transtorno ObsessivoCompulsivo na Infância e Adolescência, Imunopatologia em Doenças Psiquiátricas, Diagnósticos e Instrumentos de Avaliação etc.

A equipe responsável é composta pelo Prof. Dr. Valentim Gentil, que é o Coordenador Chefe, e pela Profa. Dra. Clarice Gorenstein, Vice-Coordenadora. Apresenta uma equipe de pesquisadores composta por professores livres-docentes, doutores e mestres, e suas publicações científicas deram ao LIM 23 o número de 2.263 citações internacionais de seus artigos, denotando a competência e o valor dessa equipe, bem como o reconhecimento internacional de seus trabalhos.

Mais informações: lim23@ig.com.br

\section{PRATO}

No segundo semestre de 1993, o Prof. Dr. Arthur Kaufman criou o PRATO dentro do Instituto de Psiquiatria do Hospital das Clínicas da Faculdade de Medicina da USP.

Sendo a obesidade uma doença multifatorial, a proposta foi desenvolver um trabalho de caráter multiprofissional, que prioriza a abordagem dinâmica da obesidade, atenta às causas e fatores de manutenção, ao "estilo de vida", e não exclusivamente à extinção de seus sintomas. A proposta do PRATO é a alteração da qualidade de vida por meio de um processo que inclui autoconhecimento, melhora da auto-imagem e da autoestima. $\mathrm{O}$ instrumento de trabalho utilizado é a abordagem conjunta sob diversas óticas: avaliação clínicoendocrinológica, psicoterapia grupal de base psicodinâmica, educação física, nutrição, biodança e dança-doventre. Além dos atendimentos no Instituto de Psiquiatria, a equipe do PRATO também desenvolve pesquisas com o intuito de sistematizar e dar um caráter científico a suas descobertas, sempre buscando inovar e encontrar melhores caminhos para o tratamento da obesidade. $\mathrm{O}$ PRATO oferece ainda cursos e seminários, bem como trabalhos direcionados a grupos específicos, como empresas e escolas. Sob a coordenação do Prof. Dr. Arthur Kaufman trabalham no PRATO médicos, psicólogas, nutricionistas, professores de educação física, terapeutas ocupacionais e professoras de dança.

Mais informações:

akaufman@globo.com

afkaufman@uol.com.br

\section{ProSex}

Em 1984, Carmita H. N. Abdo publicou na Revista Paulista de Medicina (hoje São Paulo Medical Journal) o resultado de um levantamento diagnóstico que fez na Coordenadoria de Saúde e Assistência Social da Universidade de São Paulo (COSEAS). Naquela ocasião, constatou-se que 11 dos 107 universitários que lá iniciaram tratamento, durante o ano de 1983, o fizeram em função do diagnóstico de Transtornos da Sexualidade. Esse número crescia para $80 \%$ dos casos quando se raciocinava em termos de algum tipo de comprometimento neste campo, ainda que não sendo o principal diagnóstico. A partir desse trabalho, foi feito um estudo mais amplo a respeito da sexualidade da população de alunos da Universidade de São Paulo, matriculados para acompanhamento na COSEAS, no período de 1977 a 1984. Desse estudo resultou a tese de doutorado de Carmita H. N. Abdo, sob o título Aspectos da Sexualidade de uma População Universitária.

A boa repercussão desse trabalho no meio acadêmico e a importância do tema, tratado estritamente do ponto de vista médico, motivaram Carmita Abdo a criar, em 1993, o Projeto Sexualidade (ProSex) dentro do Instituto de Psiquiatria do Hospital das Clínicas da FMUSP. Para isso organizou uma equipe multidisciplinar - constituída por psiquiatras, urologistas, ginecologistas, psicólogos, terapeutas ocupacionais, assistentes sociais e residentes de psiquiatria - destinada a assistência, ensino, pesquisa e prevenção dos transtornos da sexualidade.

As áreas de interesse do ProSex são: sexualidade humana, transtornos da sexualidade, educação sexual, abordagem do casal e da família, a sexualidade e o desenvolvimento na infância, na adolescência, na gravidez, no climatério, na andropausa e na terceira idade, sexualidade do paciente psiquiátrico, sexualidade do paciente clínico, sexualidade do reabilitado físico, sexualidade e relação médico-paciente etc.

Atualmente, já se inscreveram para tratamento no ProSex milhares de homens e mulheres.

Entre as atividades assistenciais destacam-se o Ambulatório Didático, em que médicos residentes atendem sob supervisão, o atendimento urológico e o ginecológico, feitos pelos profissionais especialistas da equipe, $\mathrm{o}$ atendimento psiquiátrico e o psicoterápico etc.

A equipe coordenada pela Profa. Dra. Carmita H. N. Abdo é composta por vários urologistas, vários ginecologistas, mais de dez pós-graduandos com teses já defendidas ou em elaboração, médicos residentes do $2^{2} \underline{ }$ ano, médicos assistentes comissionados etc. Fornece uma equipe de mais de 20 psicólogas para atendimento no Disk-ProSex, em que a população pode tirar suas dúvidas 
e receber orientações. Apresenta uma equipe de trabalhos de campo para pesquisas, bem como a equipe do Sexperts (respostas a $e$-mails). Há também uma equipe responsável pelo site www.portaldasexualidade.com.br, em que a população buscará conhecimento e orientação de transtornos sexuais, bem como informações técnicas para profissionais de saúde.

O ProSex tem organizado simpósios sobre sexualidade, além de organizar projetos em equipe com o GREA, como, por exemplo, o projeto Uso de Drogas e Comportamento Sexual de Alunos da Rede de Ensino Público do Estado de São Paulo. O ProSex tem publicado artigos em periódicos nacionais e internacionais. Em 1997, lançou a primeira edição do livro Sexualidade Humana e seus Transtornos, organizada pela Profa. Dra. Carmita H. N. Abdo.

Esse projeto desenvolveu, entre 2000 e 2001, sob a coordenação da Profa. Dra. Carmita H. N. Abdo, a maior pesquisa já feita no Brasil sobre o tema: O Estudo do Comportamento Sexual do Brasileiro (ECOS), que contou com a participação de quase 3 mil indivíduos (homens e mulheres) de várias cidades do país. Os dados referentes a esse estudo foram publicados em revistas nacionais e internacionais.

Mais informações: prosexmail@uol.com.br

\section{AMBULIM}

O Ambulatório de Bulimia e Transtornos Alimentares (AMBULIM) do Instituto de Psiquiatria do Hospital das Clínicas da FMUSP foi criado no primeiro semestre de 1992, quando não havia no Brasil nenhum centro especializado no tratamento dos transtornos alimentares, com base nos modelos criados pelo Prof. G. F. Russell na sessão de Transtornos Alimentares do Instituto de Psiquiatria da Universidade de Londres, pelo Prof. C. P. L. Freeman da Universidade de Edimburgo e pelo Prof. A. H. Crisp do Hospital St. George.

O organizador e Coordenador Geral do AMBULIM, Prof. Dr. Táki Athanássios Cordás, e sua equipe procuraram formular um modelo de atendimento adaptável às condições do Instituto de Psiquiatria do Hospital das Clínicas da FMUSP e do país como um todo. Praticamente dez anos após a sua fundação, o AMBULIM é o maior centro especializado em transtornos alimentares do Brasil e da América Latina, oferecendo tratamento totalmente gratuito para pacientes originários de qualquer ponto do país. Esse tratamento especializado dos transtornos alimentares também exige uma abordagem multiprofissional.

As áreas de atuação do AMBULIM são: anorexia nervosa, bulimia nervosa, obesidade e suas complicações psiquiátricas, comer compulsivo etc.
Promove atividades assistenciais: Ambulatório de Anorexia e Bulimia Nervosas, Ambulatório de Obesidade e Comer Compulsivo (AMBESO), Ambulatório de Transtornos Alimentares da Infância e Adolescência (PROTAD), enfermaria de transtornos alimentares, e hospital-dia.

Promove também atividades de ensino, serviços à comunidade, projetos de pesquisa e projetos de ampliação do AMBULIM.

O AMBULIM, por intermédio de seu Coordenador Geral, Prof. Dr. Táki Athanássios Cordás, e sua equipe tem publicado livros científicos e livros para a comunidade sobre os temas especializados. Atualmente, o AMBULIM é constituído por médicos, pós-graduandos, residentes, psicólogos, nutricionistas etc.
Mais informações:
ambulim@hcnet.usp.br ou
takicordás@usp.br

\section{GRUDA}

A partir das conclusões do Simpósio Internacional sobre Lítio, realizado em São Paulo, em 1983, um grupo de residentes do Instituto de Psiquiatria do HC-FMUSP criou o Grupo de Estudos de Doenças Afetivas - GRUDA -, com o objetivo de estudar, pesquisar e difundir o conhecimento sobre os transtornos do humor. As evidências na época mostravam que poucos pacientes bipolares estavam em tratamento profilático com lítio e esse fato preocupante impulsionou essa tarefa.

Após 19 anos de trabalho, o GRUDA hoje é o centro de referência nacional para transtornos do humor.

O Prof. Dr. Ricardo Alberto Moreno, Coordenador Geral do GRUDA, e uma equipe de profissionais especializados, como os Profs. Drs. Beny Lafer, Frederico Navas Demetrio e muitos outros, desenvolveram atividades assistenciais de ensino e de pesquisa.

As áreas de interesse no GRUDA são: aspectos clínicos, terapêuticos e psicossociais das depressões e do transtorno bipolar do humor; Psiquiatria Biológica, Psicofisiologia Clínica e psicoses em geral; Psicofarmacologia de antidepressivos, antipsicóticos e estabilizadores do humor.

O GRUDA promove programa educacional com elaboração e distribuição de manuais educativos para pacientes e familiares portadores de transtornos do humor. Criou a ABRATA - Associação Brasileira de Familiares, Amigos e Portadores de Transtornos Afetivos -, sem fins lucrativos, que busca melhorar a qualidade de vida dos portadores de depressão e transtorno bipolar do humor. 
Quanto às atividades de ensino, procura atualizar o conhecimento na área dos transtornos de humor, promover intercâmbio com outros centros de ensino e disseminação de conhecimentos advindos do trabalho do grupo.

Muitos projetos de pesquisa se transformaram em dissertações de mestrado e teses de doutorado em número superior a dez.

Mais informações: rmoreno@sti.com.br

\section{NEPER}

As dimensões espirituais e religiosas da cultura estão entre os fatores mais importantes que estruturam a experiência humana, as crenças, os valores, o comportamento e os padrões de adoecimento. Autores internacionais, a partir da década de 1990, já se posicionaram para que a Psiquiatria se interessasse por esse tema, não somente nos seus aspectos patológicos, como também nos seus aspectos normais. Entre nós, escrevi, em 1996, o livro Psicoterapia e Religião. Francisco Lotufo Neto, em 1997, defendeu uma tese de livre-docência na Faculdade de Medicina da USP cujo título foi Psiquiatria e Religião: a Prevalência de Transtornos Mentais entre Ministros Religiosos. A partir daí, Alexander Moreira de Almeida, Hyong Jin Cho, residentes de Psiquiatria, Lotufo e eu resolvemos criar um núcleo de estudos para pesquisar problemas espirituais e religiosos: organizamos o NEPER (Núcleo de Estudos de Problemas Espirituais e Religiosos). Seu objetivo é o estudo, a pesquisa e a assistência sobre questões religiosas e espirituais, segundo o enfoque científico, quer essas questões se apresentem com aspectos psicopatológicos ou apenas pequenos transtornos de emoções. Atualmente está sob a coordenação e liderança de Alexander Moreira de Almeida, que tem promovido reuniões com convidados nacionais e internacionais.

$$
\begin{aligned}
& \text { Mais informações: } \\
& \text { alexma@usp.br } \\
& \text { ectipq@ hotmail.com }
\end{aligned}
$$

\section{Interconsultas}

O Grupo de Interconsultas iniciou suas atividades em 1979, prestando atendimento psiquiátrico sistematizado aos pacientes internados nas outras unidades do Hospital das Clínicas. Essa atividade, até então, era realizada pelo médico de plantão do Instituto de Psiquiatria. Arthur e Laura Guerra de Andrade, nessa época residentes de primeiro ano, foram os idealizadores do grupo que, com o apoio de Paulo Vaz de Arruda, docente do Departamento de Psiquiatria da FMUSP, iria constituir-se no primeiro grupo especializado do Instituto de Psiquiatria. A partir de 1983, o grupo passou a ser coordenado por Luiz Roberto Millan e Eurípides Constantino Miguel Filho. Nesse período, as principais atividades do grupo incluíam reuniões semanais para discussão de casos atendidos e de artigos científicos. Em decorrência da necessidade de divulgação do tema no Brasil, em 1987, seus integrantes organizaram o I Congresso Brasileiro de Psiquiatria e Medicina Interna reunindo cerca de mil participantes, entre os quais quatro conferencistas estrangeiros. Desse evento, surgiu o livro Psiquiatria e Medicina Interna, que por muito tempo foi a principal referência nacional sobre o assunto. Com a participação de integrantes de líderes de várias partes do país, o Grupo de Interconsultas realizou, em 1989, o I Encontro Brasileiro de Interconsulta Psiquiátrica, o qual também gerou um livro. Esse evento foi fundamental para o crescimento da área de interconsultas fora do Instituto. Entre as suas principais consequiências, em 1992, foi criado o Departamento de Interconsulta da Associação Brasileira de Psiquiatria. Desde essa época, o departamento vem repetindo esses encontros nacionais em vários Estados, ampliando e atualizando os conhecimentos sobre a interconsulta. A partir de 1987, os residentes do Departamento de Psiquiatria passaram a estagiar no Grupo de Interconsultas, recebendo supervisão semanal. Como reflexo da melhora técnica e assistencial, a demanda anual de casos novos, que era cerca de 130 no início da década de 1980, chegou a 300 dez anos depois.

Em 1992, Eurípides Miguel, após coordenar o grupo por mais de dez anos, foi fazer seu pós-doutorado no exterior, deixando a coordenação do grupo para Renério Fráguas Júnior, que assume esta posição até hoje.

Estimulado por Valentim Gentil Filho, em 1993, iniciou-se o projeto de interconsulta no pronto-socorro. Com o objetivo de propiciar treinamento específico em urgência, os residentes passaram a acompanhar diariamente as atividades do PS, atendendo de modo mais integrado e ágil as interconsultas psiquiátricas.

Em 1997, o Grupo de Interconsultas iniciou uma série de atividades enfocando a associação da depressão com outras condições não-psiquiátricas. Foram organizados simpósios internacionais. De todas essas experiências, vários livros especializados foram publicados, entre eles o livro Depressões Secundárias, tendo como editores Renério Fráguas Júnior e João Augusto Bertuol, com a colaboração de 120 especialistas.

Em 1999, sob a coordenação da psicóloga Mara Cristina Souza de Lucia (idealizadora), diretora da Divisão de Psicologia do Instituto Central do HC, e de Renério Fráguas Júnior, o Grupo, em conjunto com 
aquela Divisão, passou a realizar o Curso de Especialização em Psicologia no Hospital Geral.

No ano de 2001, o Grupo de Interconsultas iniciou o Programa da Equipe de Assistentes de Interconsulta em Emergências. Esse programa tornou-se viável graças ao trabalho em conjunto com o Diretor Clínico do Instituto de Psiquiatria, Edson Shigemi Hirata. Nesse novo modelo, um assistente passou a dar plantão diariamente no pronto-socorro do Instituto Central.

Ao longo dos seus 22 anos de existência, o Grupo de Interconsultas trouxe significativa contribuição para a história do Instituto de Psiquiatria. Além de ter sido o primeiro grupo especializado, demonstrou a evidente necessidade da participação do psiquiatra no Hospital Geral. Como resultado, surgiu a contratação recente de profissionais ligados ao Grupo Interconsultas para prestar assistência no Pronto-Socorro do Hospital das Clínicas. Sua liderança ultrapassou ou limites do Hospital das Clínicas e foi fundamental para a criação de um Departamento Nacional na Associação Brasileira de Psiquiatria. Nos últimos anos, o grupo caminhou no sentido de desenvolver pesquisas especializadas, conseguindo apoio de entidades como FAPESP e gerando publicações internacionais.

Apresentou, até agora, oito livros publicados sobre o assunto, bem como vinte capítulos de livros. Cerca de 18 artigos científicos foram publicados sobre o tema até o momento.

Mais informações: rfraguas@ @cnet.usp.br

\section{Centro de Pesquisa e Treinamento em Diagnóstico Psiquiátrico}

Coordenadora: Dra. Laura Helena Silveira Guerra de Andrade.

O Centro de Pesquisa e Treinamento em Diagnóstico Psiquiátrico é parte do Centro Colaborador da OMS para Pesquisa e Treinamento em Saúde Mental do Departamento de Psiquiatria da FMUSP e do LIM 23. Tem suas atividades voltadas à pesquisa em Epidemiologia Psiquiátrica como treinamento em instrumentos diagnósticos (agrega o WHO Designated Brazilian SCAN Training and Reference Center), estudos de validação de escalas de avaliação, além de estudos sobre ocorrência de transtornos mentais e dos fatores de risco associados a eles na população geral. $\mathrm{O}$ Centro está voltado às atividades de pós-graduação, contando atualmente com quatro alunos do programa de doutorado em Psiquiatria.

Foi criado, em 1987, como Centro de Treinamento no Sistema PSE/SCAN/CATEGO, o qual recebeu auxílio da FAPESP para ser equipado, e contou, na época, com a supervisão acadêmica do Prof. Dr. Valentim Gentil e do Centro de Coordenação de Pesquisas e Treinamento no Instrumento, sediado no MRC Social Psychiatry Unit, Institute of Psychiatry, University of London. Reconhecido como World Health Organization designed SCAN Training and Reference Center no Brasil, participou em 1989 e 1990 do desenvolvimento e testes de campo da versão atual do instrumento (SCAN Field Trial Center; Dra. Laura Helena S. G. de Andrade e Prof. Dr. Francisco Lotufo Neto foram treinados no centro de Londres do Institute of Psychiatry [IoP] pelo Dr. Paul Bebbington, em estágios de dois meses, com bolsa do Conselho Britânico, do intercâmbio entre o IoP e o IPq). O Centro realiza, desde 1987, dois cursos por ano de treinamento no instrumento, de duração de 40 horas, para psiquiatras e psicólogos clínicos do país e da América Latina.

Numerosos autores de teses de doutorado defendidas no programa de pós-graduação utilizaram o PSE/ SCAN como instrumento para coleta de informações e diagnóstico.

A Dra. Laura H. S. G. de Andrade, estudando a co-morbidade entre transtorno de pânico e depressão, utilizou o instrumento em uma amostra clínica para sua tese de doutorado. Participou do Programa de PósDoutorado no Departamento de Saúde Mental da Escola de Saúde Pública da Johns Hopkins University, de agosto de 1991 a julho de 1992, tendo como supervisor no exterior o Professor Doutor William W. Eaton, ph.D. e bolsa de doutorado-sanduíche do CNPq. Durante esse estágio, analisou os dados do estudo epidemiológico Epidemiologic Catchment Area Study, verificando o padrão de co-morbidade entre ataque de pânico e depressão nessa amostra da população geral americana. De volta ao Brasil, coordenou, juntamente com o Prof. Doutor Valentim Gentil, em colaboração com a Faculdade de Saúde Pública da USP, na pessoa da Profa. Doutora Cecília de Lólio e do Prof. Doutor Rui Laurenti, o Estudo Epidemiológico da Área de Captação do Hospital das Clínicas - FMUSP. Esse projeto foi financiado pela FAPESP (Projeto Temático 93/0501-4) e teve a duração de quatro anos, de fevereiro de 1994 a fevereiro de 1998. A coleta de dados foi realizada nos anos de 1995 e 1996.

Foi utilizado como instrumento do estudo de área de captação a entrevista CIDI (Composite International Diagnostic Interview; Robins et al., 1988), com 1.464 indivíduos. O CIDI é uma entrevista estruturada para ser aplicada por entrevistadores leigos em sujeitos da população geral, desenvolvida pela Organização Mundial da Saúde, com o objetivo de permitir estudos comparativos entre diversos países. A entrevista SCAN foi 
utilizada em entrevistas realizadas por psiquiatras do IPq na comunidade, para a reavaliação clínica e validação das informações obtidas através do CIDI (em 390 sujeitos).

Em maio de 1995, durante apresentação de dados preliminares da reavaliação clínica dos casos de depressão (Use of SCAN in Comparison to CIDI in a Catchment Area in São Paulo - Brazil. Andrade L, Lólio C, Gentil V, Laurenti R \& Werebe D), no Simpósio SCAN: Robust Tool for Epidemiological Studies, durante o encontro bienal da World Psychiatric Association, Section of Epidemiology \& Community Psychiatry, realizado em Nova York, a Dra. Laura Andrade foi convidada a participar da formação de um consórcio de pesquisadores em epidemiologia psiquiátrica que haviam utilizado, estavam utilizando ou pretendiam utilizar o CIDI em estudos populacionais: International Consortium in Psychiatric Epidemiology (ICPE).

Patrocinado pelo U.S. National Institute of Health, o objetivo do Consórcio é a comparação cross-cultural de estudos epidemiológicos acerca de transtornos psiquiátricos. Os coordenadores do consórcio são: Ronald Kessler, Professor (Chairman) do Departamento Health Care Police da Faculdade de Medicina da Universidade de Harvard (quem realizou o National Comorbidity Survey), e Bedirhan Üstun, da Divisão de Saúde Mental da Organização Mundial da Saúde. A administração é feita pelo Institute for Social Research na Universidade de Michigan. Desde 1996, vem ocorrendo encontros anuais. A proposta do Consórcio é congregar pesquisadores em saúde mental e formar um grande banco de dados, base de estudos comparativos, verificando similaridades e diferenças entre as apresentações dos transtornos mentais em diferentes culturas. Várias publicações relativas a esses estudos comparativos foram publicadas e outras estão no prelo.

Atualmente, os esforços da coordenação do Centro estão concentrados na elaboração de um projeto temático FAPESP para a realização de um estudo epidemiológico na Região Metropolitana de São Paulo.

O Centro de Pesquisa e Treinamento em Diagnóstico Psiquiátrico apresenta várias linhas de pesquisa: Co-morbidade entre ansiedade e depressão, aspectos diagnósticos dos transtornos de ansiedade, aspectos diagnósticos dos transtornos do humor, escalas e instrumentos de avaliação e epidemiologia psiquiátrica.

Apresenta muitos projetos em andamento, como por exemplo WMHS-Brazil - Estudo Epidemiológico dos Transtornos Mentais no Estado de São Paulo: Prevalência, Fatores de Risco e Sobrecarga Social e Econômica. Segmento brasileiro do World Mental Health Survey de Organização Mundial da Saúde, e muitos outros projetos.

Devido à competência desse Centro, bem como às citações internacionais de seus artigos, diversas insti- tuições, como FAPESP e The Wellcome Trust, têm fornecido auxílio substancial para as pesquisas.

Bolsas de doutorado no país e no exterior são fornecidas a componentes desse Centro, que produziu cerca de 24 artigos com repercussões nacionais e internacionais. Como exemplo, temos a Dra. Laura Helena Silveira Guerra de Andrade, que apresenta cerca de 133 citações de seus artigos internacionais. O Centro, por intermédio de Clarice Gorenstein, Laura H. S. G. de Andrade e Antonio W. Zuardi, publicou um livro especializado em Escalas de Avaliação Clínica em Psiquiatria e Psicofarmacologia. Além de contribuir com dezenas de artigos em capítulos de livros, o Centro, bem como sua equipe, se fez presente com apresentações orais e pôsteres em cerca de 14 reuniões internacionais.

Para informações adicionais: lhsgandr@usp.br

\section{Setor de Eletroconvulsoterapia}

Antes da construção do Instituto de Psiquiatria, o Prof. Pacheco e Silva, em 1941, já publicava seus primeiros resultados sobre a eficácia da eletroconvulsoterapia.

Em 1952, realizou-se a primeira sessão de eletroconvulsoterapia, no então chamado Prédio da Psiquiatria. Foi realizado pelo Dr. Henrique Marques de Carvalho, o responsável pelo serviço. Os tratamentos eram realizados sem anestesia. Em 1965, foi inaugurado o hospital-dia, que no início era dirigido pelo Dr. Jayme Gonçalves, onde se aplicava a eletroconvulsoterapia.

Apesar de controvérsias sobre a aplicação da eletroconvulsoterapia, o Prof. Pacheco e Silva sempre insistiu em sua aplicação. Certa ocasião, já como Professor Emérito, dirige-se a um estagiário (hoje nosso colega Dr. S. P. Rigonatti) e aconselha-o: "O método de Cerletti não pode ser abandonado; procure estudá-lo".

No início da década de 1970, a eletroconvulsoterapia já era executada com anestesia no Instituto de Psiquiatria. Com o evoluir do Instituto de Psiquiatria, já na gestão do Prof. Valentim Gentil como Titular, foi criado um Núcleo de Estudos em Eletroconvulsoterapia, com instalações próprias e aparelhos de última geração. Os tratamentos passaram a ser realizados em condições de segurança excepcionais. O Serviço passou a contar com cinco anestesistas e o "consentimento informado" foi instituído, inclusive com a projeção de um filme que o paciente e a família assistem antes de assiná-lo.

O Dr. Sergio Paulo Rigonatti, atual responsável pelo Serviço de Eletroconvulsoterapia, tem contribuído para a maior aceitação desse tratamento nos meios acadêmicos, e publicou, juntamente com o Dr. Moacir A. Rosa: Indicações e Prática da Eletroconvulsoterapia. 
Rigonatti introduziu uma sessão de arteterapia no pré-ECT com a finalidade de não só diminuir a ansiedade, como também para acompanhar a melhora dos pacientes através dos desenhos. Atualmente associou-se ao grupo uma musicoterapeuta. O Núcleo de Estudos em Eletroconvulsoterapia tem se expandido em suas pesquisas, promovendo artigos especializados.

Para informações adicionais:

ectipq@hotmail.com

\section{NUFOR}

Em 1994, Valdir Pricolli, Antonio Carlos Justino Cabral e Sergio Paulo Rigonatti fundaram o Centro de Estudos Interdisciplinar de Psiquiatria e Direito. Vários temas foram pesquisados, como por exemplo Início Médico-Legal da Esquizofrenia, Aspectos Psiquiátricos Forenses do Alcoolismo, Simulação e Dissimulação dos Sintomas Psíquicos, Personalidades Psicopáticas etc.

No ano seguinte, o grupo reuniu-se com Valentim Gentil Filho para conceituar as metas e as finalidades do Núcleo de Estudos e Pesquisas em Psiquiatria Forense e Psicologia Jurídica - NUFOR - e, nessa ocasião, outros profissionais se agregaram à equipe. A seguir, foi elaborado um programa para curso de pós-graduação em Psiquiatria e Direito.

Dois anos depois, o grupo se firmou como equipe, coordenada por Sergio Paulo Rigonatti e Maria Adelaide de Freitas Caíres.

A consolidação do núcleo propiciou, entre suas primeiras conquistas, a criação do Curso de Psiquiatria Forense, com temas em Psicologia Jurídica, que passou a fazer parte da grade curricular do segundo ano de residência do Instituto de Psiquiatria em 1997. Em junho de 2001, foi realizada a Assembléia Geral de fundação do NUFOR, com a aprovação dos estatutos e formalização do quadro de participantes. Expandindo sistematicamente suas atividades, vem desenvolvendo novos projetos de pesquisa, elaborando publicações e firmando parcerias com entidades públicas e privadas. O Núcleo de Estudos e Pesquisas em Psiquiatria Forense e Psicologia Jurídica está aparelhado para cumprir suas atribuições acadêmicas e enfrentar os desafios sociais do século XXI.

Para mais informações:

ectipq@hotmail.com

\section{PROTER}

O Projeto Terceira Idade - PROTER - tem como Coordenador Geral o Prof. Dr. Cássio Machado de
Campos Bottino, como Coordenadora do Ambulatório a Profa. Dra. Mônica Zavaloni Scalco e como Coordenador da Enfermaria o Dr. Alberto Stoppe Júnior.

O PROTER foi fundado em janeiro de 1994 como um grupo de pesquisa na área de saúde mental de idosos. Os médicos fundadores do grupo foram os Drs. Alberto Stoppe Jr., Cássio M. C. Bottino, Edson S. Hirata, Mônica Z. Scalco, Orestes V. Forlenza e Osvaldo P. Almeida, que foi o primeiro coordenador do PROTER. A partir de 1995, as atividades do grupo foram ampliadas com a criação do Ambulatório Assistencial Didático para expandir o atendimento e permitir o treinamento em serviço de médicos residentes. Em 1996, começou a funcionar a Clínica de Memória do PROTER, prestando atendimento multidisciplinar a pacientes de qualquer faixa etária que procurem o Instituto de Psiquiatria com queixas relacionadas às funções cognitivas. Em 1997, tiveram início as atividades da enfermaria do PROTER, inicialmente com quatro leitos, visando prestar tratamento hospitalar a pacientes acima de 60 anos com transtornos psiquiátricos graves.

Os objetivos do PROTER são, principalmente, promover pesquisa na área de saúde mental do idoso, treinar profissionais médicos e não médicos para atividade assistencial e de pesquisa na área de saúde mental de idosos, oferecer atendimento e tratamento na área de saúde mental a pacientes com mais de 60 anos de idade, treinamento e supervisão de residentes do Instituto de Psiquiatria do HC da FMUSP no atendimento clínico de pacientes idosos do ambulatório e enfermaria e, finalmente, promover difusão de informação sobre temas associados à área de saúde mental do idoso, mediante a organização de cursos e eventos científicos.

O PROTER promove pesquisa clínica na área de saúde mental do idoso (demências, alcoolismo, transtornos psicóticos, transtornos depressivos e ansiosos), incluindo neuropsiquiatria clínica, neuroimagem, neuropsicologia, genética, epidemiologia, ensaios clínicos, psicoterapia e atenção a cuidadores.

A equipe atual do PROTER é constituída por médicos, fonoaudiólogos, psicólogos, pós-graduandos, além dos coordenadores.

O ambulatório didático do PROTER vem recebendo residentes do segundo e terceiro ano do IPq e de outros Estados brasileiros e da América do Sul.

A Clínica de Memória é uma iniciativa pioneira no Brasil, um dos países que têm apresentado um dos maiores crescimentos proporcionais de sua população acima de 60 anos, em todo o mundo. O objetivo se direciona no sentido de: diagnóstico diferencial da síndrome demencial, diagnóstico precoce da doença de Alzheimer e demências de outras etiologias, estudo 
longitudinal de pacientes com transtorno cognitivo leve, investigação de fatores de risco para demência, desenvolvimento/validação de instrumento para auxiliar o diagnóstico clínico, tratamento medicamentoso, reabilitação cognitiva e orientação familiar.

$\mathrm{Na}$ enfermaria são aceitos casos encaminhados dos ambulatórios para pacientes com mais de 60 anos, com doenças predominantemente psiquiátricas para tratamento em fase aguda ou reagudização e com necessidade de avaliação ou intervenção rápida, ou mesmo cuidados específicos quando isso não for possível em ambulatório, casos de interesse acadêmico e científico etc.

O PROTER fornece um grupo de reabilitação neuropsicológica, bem como um grupo de arteterapia.

Quanto ao ensino, o PROTER organiza seminários para médicos residentes e colaboradores, e os integrantes do PROTER ministram aulas eventuais aos alunos do $4^{\circ}$ ano da FMUSP, bem como para as aprimorandas do Serviço de Psicologia.

Quanto às atividades de pesquisa realizadas no PROTER ou com participação efetiva de integrantes do grupo, podemos acusar cerca de 12 projetos de pesquisa.

A produção científica da equipe do PROTER tem sido reconhecida por meio das citações de seus artigos publicados. Como exemplo, temos Cássio M. C. Bottino, que, com cerca de 15 artigos publicados, apresenta nove citações no ISI Web of Science.

Dissertações de mestrado e teses de doutorado surgiram dentro dessa equipe: Influência do Processo de Envelhecimento no Quadro Clínico de Depressão em Idosos, Alberto Stoppe Júnior em nível de mestrado, apresentada em 1995; Demência do tipo Alzheimer, Transtorno Cognitivo Leve e Envelhecimento Normal: um continuum? Contribuição ao Estudo de Aspectos Clínicos e de Neuroimagem, Cássio M. C. Bottino, nível de doutorado, apresentada em 1997; Efeitos da Nortriptilina sobre a Pressão Arterial de Idosos Deprimidos Hipertensos e Normotensos, Mônica Zavaloni Scalco, nível de doutorado, apresentada em 1998.
O PROTER coopera com outras instituições ou Serviços, como por exemplo: Departamento de Neurologia, Instituto do Coração, Instituto de Radiologia, Medicina Nuclear, Clínica Médica etc. Há também cooperadores internacionais, e os principais são: Dan G. Blazer, MD, Ph.D. - Professor de Psiquiatria da Faculdade de Medicina da Universidade de Duke, Carolina do Norte, EUA; John C. S. Breitner, MD, $\mathrm{MPh}$ - Professor e Chefe do Departamento de Higiene Mental da Universidade Johns Hopkins, Baltimore, EUA; Antonio Convit, MD - Pesquisador do Laboratório de Neuroimagem da Universidade de Nova York, Nova York, EUA; e Norbert Schuff, Ph.D. - Professor de Radiologia da Universidade da Califórnia, São Francisco, EUA.

O PROTER tem obtido bolsas de estudos no exterior, como por exemplo o doutorado-sanduíche para estágio em sete meses na Section of Old Age Psychiatry, no Instituto de Psiquiatria de Londres, que Cássio Bottino obteve pelo CNPq, bem como o estágio de Pesquisa em Psiquiatria Geriátrica, de seis meses, concedido pela International Psychogeriatric Association, no Instituto de Psiquiatria de Londres, obtido por Orestes Vicente Forlenza.

O PROTER tem publicado livros cujos temas estão relacionados a transtornos no idoso.

Para informações adicionais: cbottino@usp.br

Ao terminar este resumo histórico do Departamento de Psiquiatria e do Instituto de Psiquiatria, sinto que não pude comunicar todo o ocorrido no passado e no presente, pois, além de ser uma tarefa impossível forneceram-me 30 dias de prazo para tal. Procurei dados de fontes escritas, de minha própria vivência dentro do Instituto e do Departamento, de entrevistas com os responsáveis por setores e grupos de pesquisa, relatos por escrito fornecidos pelos responsáveis por setores do Instituto e do Departamento, e principalmente por um artigo de minha autoria, escrito no passado, sobre a História do Departamento de Psiquiatria e do Instituto de Psiquiatria.

Geodon (cloridrato de ziprasidona) é um novo antipsicótico para o tratamento da esquizofrenia. A ziprasidona é um antagonista dos receptores de serotonina $5 \mathrm{HT}_{24} \mathrm{e}$ de dopamina $\mathrm{D}_{2}$. Sugere-se que sua eficácia antipsicótica seja mediada por esse mecanismo de ação. Indicações: para o tratamento da esquizofrenia, transtornos esquizoafetivo e esquizofreniforme, estados de agitação psicótica e mania bipolar aguda, para a manutençăo da melhora clínica e prevenç̧äo de recidivas, durante a continuação da terapia. Foi demonstrada a eficáci da ziprasidona no tratamento dos sintomas positivos e negativos da esquizofrenia em pacientes hospitalizados com exacerbaçäo aguda da doença (vide bula completa do produto). Contra-indicaçóes: conhecida hipersensibilidade à ziprasidona ou a qualquer componente da fórmula. É contra-indicado a pacientes com conhecido prolongamento do intervalo QT, incluindo síndrome do QT longo, a pacientes com infarto agudo do miocárdio, insuficieiencia cardiaca descompensada ou aritimias cardiacas que necessitem de tratamento com fármacos

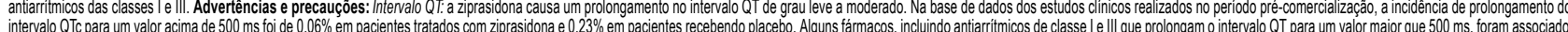
intervalo QTc para um valor acima de $500 \mathrm{~ms}$ foi de $0,06 \%$ em pacientes tratados com ziprasidona e $0,23 \%$ em pacientes recebendo placebo. Alguns fármacos, incluindo antiarritmicos de classe le lll que prolongam o intervalo QT para um valor maior que $500 \mathrm{~ms}$, foram associados com a ocorrenciala rara de taquicardia ventricular (torsade de pointes). Bradicardia, disturbios eletroliticos ou uso concomitante com outros tarmacos que prolongam o intervalo QT, podem aumentar o risco de ocorrència desta arritmia. Portanto, a ziprasidona deve ser usada com precauçao em pacientes com estes fatores de risco. Se sintomas cardiacos sugestivos de arritmias forem observados ou relatados durante o tratamento, deve ser feita uma avaliaçao cardiologica apropriada. Se e intervalo QTC encontrado for maior que 500 ms, e recomendado

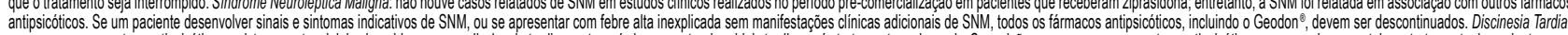
como ocorre com outros antipsicóticos, existe um potencial da ziprasidona causar discinesia tardia outras síndromes extrapiramidais tardias após tratamento prolongado. Convulsóes: como ocorre com outros antipsicóticos, recomenda-se cautela no tratamento de pacientes com histórico de convulsöes. Fármacos ativos no SNC/Áĺcool: considerando os éfeitos primários da ziprasidona no SNC, deve-se ter cautela quando esta for administrada em associação a outros fármacos de açấo central, incluindo álcool e fármacos que agem nos sistemas dopaminérgicos e serotoninérgicos. Gravidez e lactaçâa: como a experiência clínica ainda é limitada, a administraçăo de ziprasidona não é recomendada durante a gravidez, a menos que o benefício esperado para a mãe supere o risco potencial ao feto. 0 uso em lactantes não é recomendado. Geodon pode causar sonolência, portanto os pacientes devem ser advertidos adequadamente se forem dirigir ou operar outras máquinas. Reaçoes adversas: Geodon é geralmente bem tolerado. Em estudos clinicos de curto prazo, os eventos adversos associados à utilizaçäo de Geodon (ocorrendo com uma freqüência $>3 \%$ e excedendo a frequiência do placebo em $>2 \%$ ) foram: astenia, sindrome extrapiramidal, náusea, sonolência e transtorno respiratório (incluindo sintomas de coriza) (vide bula completa do produto).

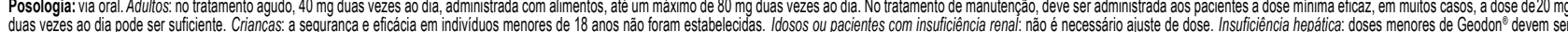

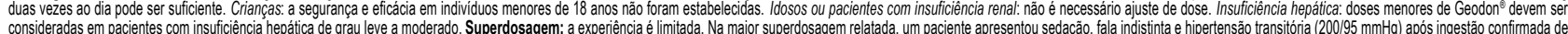

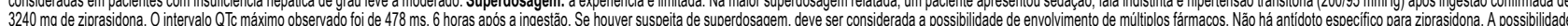

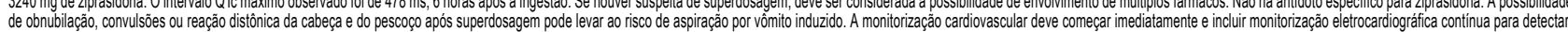

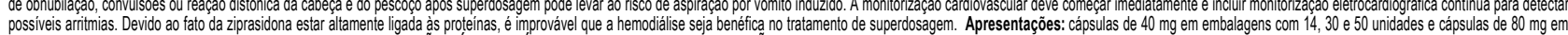
embalagem com 30 unidades. USO ADULTO. VENDA SOB PRESCRIÇÃO MÉDICA - SO PODE SER VENDIDO COM RETENÇÃO DA RECEITA. Para maiores informaçōes, Consulte a bula completa do produto (geo04). Documentação cientifica e informaçóes adicionais estäo à disposição da classe médica mediante solicitaçăo. Laboratórios Pfizer Ltda., Rua Alexandre Dumas, 1860 - Chácara Santo Antônio, São Paulo - SP. CEP 04717-904. Tel: 0800-167575 - Internet: Www. pfizer. com.br Geodon Reg. MS - 1.0216.0066 